\title{
Scrutinizing the atmospheric greenhouse effect and its climatic impact
}

\author{
Gerhard Kramm $^{1^{*}}$, Ralph Dlugi ${ }^{2}$ \\ ${ }^{1}$ Geophysical Institute, University of Alaska Fairbanks, Fairbanks, Alaska; ${ }^{*}$ Corresponding Author: kramm@gi.alaska.edu \\ ${ }^{2}$ Arbeitsgruppe Atmosphärische Prozesse (AGAP), Munich, Germany.
}

Received 23 August 2011; revised 30 September 2011; accepted 17 October 2011.

\begin{abstract}
In this paper, we scrutinize two completely different explanations of the so-called atmospheric greenhouse effect: First, the explanation of the American Meteorological Society (AMS) and the World Meteorological Organization (W.MO) quantifying this effect by two characteristic temperatures, secondly, the explanation of Ramanathan et al. [1] that is mainly based on an energy-flux budget for the Earth-atmosphere system. Both explanations are related to the global scale. In addition, we debate the meaning of climate, climate change, climate variability and climate variation to outline in which way the atmospheric greenhouse effect might be responsible for climate change and climate variability, respectively. In doing so, we distinguish between two different branches of climatology, namely 1) physical climatology in which the boundary conditions of the Earth-atmosphere system play the dominant role and 2) statistical climatology that is dealing with the statistical description of fortuitous weather events which had been happening in climate periods; each of them usually comprises 30 years. Based on our findings, we argue that 1) the so-called atmospheric greenhouse effect cannot be proved by the statistical description of fortuitous weather events that took place in a climate period, 2) the description by AMS and W.MO has to be discarded because of physical reasons, 3 ) energyflux budgets for the Earth-atmosphere system do not provide tangible evidence that the atmospheric greenhouse effect does exist. Because of this lack of tangible evidence it is time to acknowledge that the atmospheric greenhouse effect and especially its climatic impact are based on meritless conjectures.
\end{abstract}

Keywords: Physical Climatology;

Statistical Climatology; Atmospheric Greenhouse

Effect; Earth-Atmosphere System

\section{INTRODUCTION}

Recently, Gerlich and Tscheuschner [2] listed a wide variety of attempts to explain the so-called atmospheric greenhouse effect. They disproved these explanations at the hand of fundamental physical principles like the second law of thermodynamics. By showing that 1) there are no common physical laws between the warming phenomenon in glass houses and the fictitious atmospheric greenhouse effects, 2) there are no calculations to determine an average surface temperature of a planet, 3 ) the frequently mentioned difference of $33 \mathrm{~K}$ is a meaningless number calculated wrongly, 4) the formulas of cavity radiation are used inappropriately, 5) the assumption of a radiative balance is unphysical, 6) thermal conductivity and friction must not be set to zero, they concluded that the atmospheric greenhouse conjecture is falsified.

Shortly after the paper of Gerlich and Tscheuschner was published by the International Journal of Modern Physics B (IJMPB), there was an uproar in the internet (e.g., http://www.scienceblogs.de/primaklima/2009/03/ chronik-eines-angekundigten-skandals-gerlich-und-tsche uschner-wurden-peerreviewt.php, http://rabett.blogspot. com/2009/04/die-fachbegutachtung-below-is-elis.html) resulting in an uncounted attempts to insult Gerlich and Tscheuschner, even under pseudonyms as done, for instance, by Joshua Halpern (aka Eli Rabett) and Joerg Zimmermann (aka for4zim) in violating the ethical standards of scientific debates.

Halpern et al. [3] eventually wrote a comment on the paper of Gerlich and Tscheuschner [2]. They claimed that they showed that Gerlich and Tscheuschner's methods, logic and conclusions are in error. They pointed out that Gerlich and Tscheuschner did not come to grips with how the greenhouse effect emerges at levels of analysis 
typical of the modern state-of-the-art, such as from line by line calculations of atmospheric radiative transfer, global climate models (GCMs) or even on the level of advanced textbooks, but rather criticize simple, didactic models for not being complete. Furthermore, Halpern et al. argued that Gerlich and Tscheuschner made elementary mistakes. Moreover, Halpern et al. stated that these authors' lack quantitative familiarity with the field they are criticizing, second their claims of complexity or invalidity, impossibility and occasionally fraud regarding well-established quantitatively verified analyses of atmospheric processes and third their extensive diversions on topics that do nothing to further their own argument or a reader's understanding. In their reply to this comment, Gerlich and Tscheuschner [4] argued that their falsification paper discusses the violation of fundamental physical and mathematical principles in 14 examples of common pseudo-derivations of fictitious greenhouse effects that are all based on simplistic pictures of radiative transfer and their obscure relation to thermodynamics, including but not limited to those descriptions that 1) define a perpetualmotion machine of the 2nd kind, 2) rely on incorrectly calculated averages of global temperatures and 3) refer to incorrectly normalized spectra of electromagnetic radiation. They continued that Halpern et al. even did not define the greenhouse effect that they wish to defend.

It should be noticed that-based on the reviews requested by the IJMPB - the manuscript of Halpern et al. first submitted in 2009 was rejected. Surprisingly and unfortunately, it was eventually published by this journal, but none of the authors' big physical mistakes criticized by the reviewers were removed from the manuscript. The example 2.1 of Halpern et al., for instance, which is dealing with two heat reservoirs at different temperatures that exchange energy and entropy by radiation is falsified because the magnitude of the entropy flux emitted by a black body is given by $J_{s}=4 / 3 \sigma T^{3}$ [5], where $T$ is the actual surface temperature and $\sigma \cong 5.67 \times 10^{-8}$ $\mathrm{W} \cdot \mathrm{m}^{-2} \cdot \mathrm{K}^{-4}$ is Stefan's constant. Halpern et al. not only ignored Planck's [5] results, but also those of many peer-reviewed papers published during the past four decades (e.g., [6-9]). In addition, even the wrong units for irradiances and entropy fluxes used in their 2009version and already criticized by, at least, one of the reviewers were not replaced in their printed version by the correct ones. If it is possible to publish such a physically inadequate comment, we have to acknowledge that the discipline of climatology has lost its rational basis.

Is the so-called atmospheric greenhouse conjecture really falsified as Gerlich and Tscheuschner claimed and/ or is the notion "atmospheric greenhouse effect" only a misnomer in describing a real effect that may cause a climatic impact? To answer these questions two completely different explanations of the atmospheric greenhouse effect are to be scrutinized in this paper. First, the explanation of the American Meteorological Society (AMS) and the World Meteorological Organization (W·MO) quantifying the effect by two characteristic temperatures is assessed in Section 3. Secondly, the explanation of Ramanathan et al. [1] that is mainly based on an energy-flux budget is analyzed in Section 4. However, before we start to scrutinize these two different explanations we debate the meaning of climate, climate variability, climate change and climate variation in Section 2. Such a debate is required to outline in which way the atmospheric greenhouse effect might be responsible for climate variability, climate change and climate variation, respectively. In doing so, it is indispensable to distinguish between two different branches of climatology, namely 1) physical climatology in which the boundary conditions of the system Earth-Atmosphere play the most dominant role and 2) statistical climatology that is dealing with the statistical description of fortuitous weather events that had been happening in sufficiently long-term periods of the past.

\section{ON THE MEANING OF CLIMATE, CLIMATE VARIABILITY, CLIMATE CHANGE and CLIMATE VARIATIONS}

Like many other ones disputed by Gerlich and Tscheuschner in their paper [2], the explanations of the atmospheric greenhouse effect scrutinized in our contribution are related to the global scale. This relation could be the reason why often the notion "global climate" is used and the debate on climate change is mainly focused on global climate change.

The notion "global climate", however, is a contradiction in terms. According to Monin and Shishkov [10], Schönwiese [11] and Gerlich [12], the term "climate" is based on the Greek word "klima" which means inclination. It was coined by the Greek astronomer Hipparchus of Nicaea (190-120 BC) who divided the then known inhabited world into five latitudinal zones - two polar, two temperate and one tropical-according to the inclination of the incident sunbeams, in other words, the Sun's elevation above the horizon. Alexander von Humboldt in his five-volume "Kosmos" (1845-1862) added to this "inclination" the effects of the underlying surface of ocean and land on the atmosphere [10]. From this point of view one may define the components of the Earth's climate system: Atmosphere, Ocean, Land Surface (including its annual/seasonal cover by vegetation), Cryosphere and Biosphere. These components play a prominent role in characterizing the energetically relevant boundary conditions of the Earth's climate system. Other 
definitions are possible. Ocean and cryosphere, for instance, are subcomponents of the Hydrosphere that comprises the occurrence of all water phases in the Earthatmosphere system [13]. Thus, the interrelation between the solar energy input and the components of our climate system coins the climate of locations and regions subsumed in climate zones. An example of a climate classification is the well-known Köppen-Geiger climate classification recently updated by Peel et al. [14]. It is illustrated in Figure 1.

\subsection{The Boundary Conditions and Their Role in Physical Climatology}

First, we have to explain how the inclination of the incident sunbeams does affect the climate of a location or region. The solar energy reaching the top of the atmosphere (TOA) depends on the Sun's role as the source of energy, the characteristics of the Earth's elliptical orbit around the Sun (strictly spoken, the orbit of the Earth-Moon barycenter) and the orientation of the Earth's equator plane. The orbit geometry and the orientation of the equator plane are characterized by 1) the orbit parameters like the semi-major axis, $a$, the eccentricity, $e$, the oblique angle of the Earth's axis with respect to the normal vector of the ecliptic, $\varepsilon=23^{\circ} 27^{\prime}$ and the longitude of the Perihelion relative to the moving vernal equinox, $\varpi$ and 2 ) the revolution velocity and the rotation velocity of the Earth $[15,16]$. Note that $\varpi=\xi+\psi$, where the annual general precession in longitude, $\psi$, describes the absolute (clockwise) motion of the vernal equinox along the Earth's orbit relative to the fixed stars (see Figure 2) and the longitude of the Perihelion, $\xi$, measured from the reference vernal equinox of A.D. 1950.0, describes the absolute motion of the Perihelion relative to the fixed stars. For any numerical value of $\varpi, 180^{\circ}$ is subtracted for a practical purpose: observations are made from the Earth and the Sun is considered as revolving around the Earth [17,18]. Obviously, the emitted solar radiation depends on the Sun's activity often characterized by the solar cycles that are related to the number of sunspots observed on the Sun's surface (see Figure 3). However, to understand in which way the solar insolation reaching the TOA is affected by the Earth's orbit, a brief excursion through the Sun-Earth

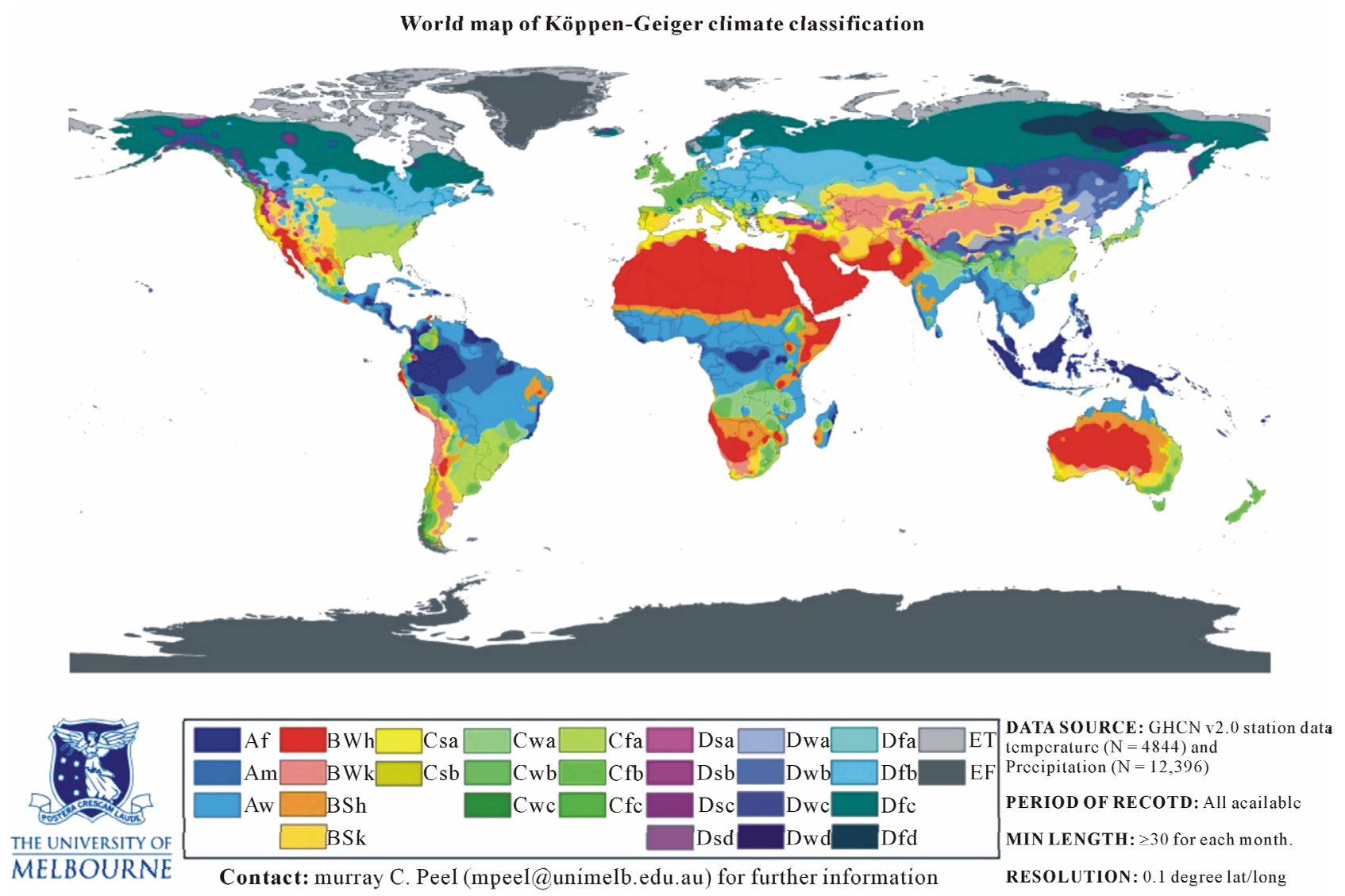

Figure 1. World map of the Köppen-Geiger climate classification (adopted from Peel et al. [14]). The 30 possible climate types in Table 1 are divided into 3 tropical (Af, Am and Aw), 4 arid (BWh, BWk, BSh and BSk), 8 temperate (Csa, Csb, Cfa, Cfb, Cfc, Cwa, Cwb and Cwc), 12 cold (Dsa, Dsb, Dsc, Dsd, Dfa, Dfb, Dfc, Dfd, Dwa, Dwb, Dwc and Dwd) and 2 polar (ET and EF). 
Table 1. Description of Köppen climate symbols and defining criteria (adopted from Peel et al. [14]).

\begin{tabular}{|c|c|c|c|c|}
\hline 1st & 2nd & 3rd & Description & Criteria* \\
\hline \multirow[t]{4}{*}{$\mathrm{A}$} & & & Tropical & $\mathrm{T}_{\text {cold }} \geq 18$ \\
\hline & $f$ & & -Rainforest & $\mathrm{P}_{\mathrm{dry}} \geq 60$ \\
\hline & $\mathrm{m}$ & & -Monsoon & Not (Af) \& $\mathrm{P}_{\text {dry }} \geq 100-\mathrm{MAP} / 25$ \\
\hline & $\mathrm{w}$ & & -Savannah & Not (Af) \& $\mathrm{P}_{\text {dry }}<100-\mathrm{MAP} / 25$ \\
\hline \multirow[t]{5}{*}{$\mathrm{B}$} & & & Arid & $\mathrm{MAP}<10 \times \mathrm{P}_{\text {threshold }}$ \\
\hline & W & & -Desert & MAP $<5 \times \mathrm{P}_{\text {threshold }}$ \\
\hline & $\mathrm{S}$ & & -Steppe & MAP $\geq 5 \times \mathrm{P}_{\text {threshold }}$ \\
\hline & & $\mathrm{h}$ & - Hot & $\mathrm{MAT} \geq 18$ \\
\hline & & $\mathrm{k}$ & -Cold & MAT $<18$ \\
\hline \multirow[t]{7}{*}{$\mathrm{C}$} & & & Temperate & $\mathrm{T}_{\text {hot }}>10 \& 0<\mathrm{T}_{\text {cold }}<18$ \\
\hline & $\mathrm{s}$ & & -Dry Summer & $\mathrm{P}_{\text {sdry }}<40 \& \mathrm{P}_{\text {sdry }}<\mathrm{P}_{\text {wwet }} / 3$ \\
\hline & $\mathrm{w}$ & & -Dry Winter & $\mathrm{P}_{\text {wdry }}<\mathrm{P}_{\text {swet }} / 10$ \\
\hline & f & & -Without dry season & Not $(\mathrm{Cs})$ or $(\mathrm{Cw})$ \\
\hline & & a & -Hot Summer & $\mathrm{T}_{\text {hot }} \geq 22$ \\
\hline & & $\mathrm{b}$ & -Warm Summer & Not (a) \& $\mathrm{T}_{\text {mon } 10} \geq 4$ \\
\hline & & $\mathrm{c}$ & -Cold Summer & Not $(\mathrm{a}$ or $\mathrm{b}) \& 1 \leq \mathrm{T}_{\operatorname{mon} 10}<4$ \\
\hline \multirow[t]{8}{*}{$\mathrm{D}$} & & & Cold & $\mathrm{T}_{\text {hot }}>10 \& \mathrm{~T}_{\text {cold }} \leq 0$ \\
\hline & $\mathrm{s}$ & & -Dry Summer & $\mathrm{P}_{\text {sdry }}<40 \& \mathrm{P}_{\text {sdry }}<\mathrm{P}_{\text {wwet }} / 3$ \\
\hline & $\mathrm{w}$ & & -Dry Winter & $\mathrm{P}_{\text {wdry }}<\mathrm{P}_{\text {swet }} / 10$ \\
\hline & f & & -Without dry season & Not (Ds) or (Dw) \\
\hline & & a & -Hot Summer & $\mathrm{T}_{\text {hot }} \geq 22$ \\
\hline & & $\mathrm{b}$ & -Warm Summer & Not (a) \& $T_{\text {mon10 }} \geq 4$ \\
\hline & & $\mathrm{c}$ & -Cold Summer & Not $(a, b$ or $d)$ \\
\hline & & d & -Very Cold Winter & Not $(\mathrm{a}$ or $\mathrm{b}) \& \mathrm{~T}_{\text {cold }}<-38$ \\
\hline \multirow[t]{3}{*}{$\mathrm{E}$} & & & Polar & $\mathrm{T}_{\text {hot }}<10$ \\
\hline & $\mathrm{T}$ & & -Tundra & $\mathrm{T}_{\text {hot }}>0$ \\
\hline & $\mathrm{F}$ & & -Frost & $\mathrm{T}_{\text {hot }} \leq 0$ \\
\hline
\end{tabular}

${ }^{*} \mathrm{MAP}=$ mean annual precipitation, $\mathrm{MAT}=$ mean annual temperature, $\mathrm{T}_{\text {hot }}=$ temperature of the hottest month, $\mathrm{T}_{\text {cold }}=$ temperature of the coldest month, $\mathrm{T}_{\text {mon10 }}=$ number of months where the temperature is above $10, \mathrm{P}_{\text {dry }}=$ precipitation of the driest month, $\mathrm{P}_{\text {sdry }}=$ precipitation of the driest month in summer, $\mathrm{P}_{\mathrm{wdry}}=$ precipitation of the driest month in winter, $\mathrm{P}_{\text {swet }}=$ precipitation of the wettest month in summer, $\mathrm{P}_{\text {wwet }}=$ precipitation of the wettest month in winter, $\mathrm{P}_{\text {threshold }}=$ varies according to the following rules (if $70 \%$ of MAP occurs in winter then $\mathrm{P}_{\text {threshold }}=2 \times$ MAT, if $70 \%$ of MAP occurs in summer then $\mathrm{P}_{\text {threshold }}=2 \times$ MAT +28 , otherwise $\mathrm{P}_{\text {threshold }}=2 \times$ MAT +14 ). Summer (winter) is defined as the warmer (cooler) six month period of ONDJFM and AMJJAS.

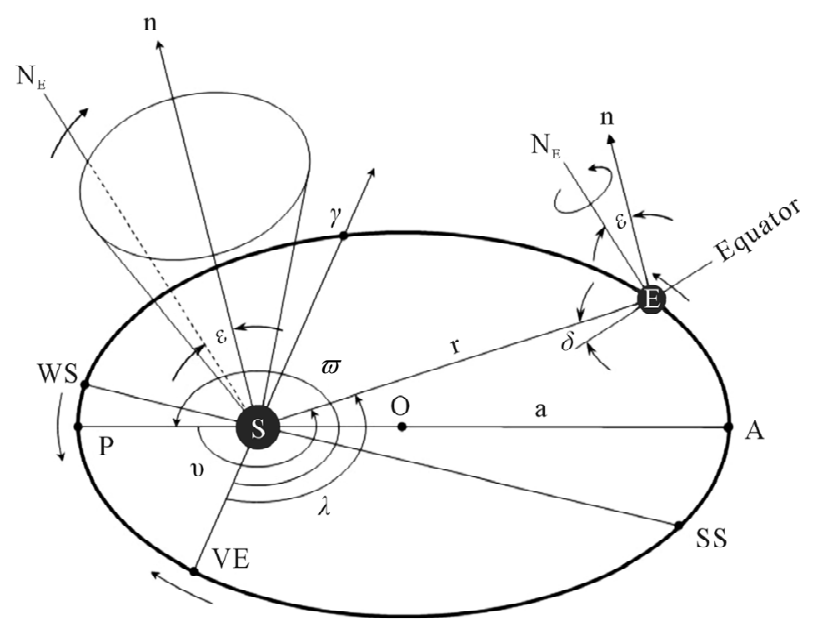

Figure 2. Elements of the Earth's orbit (with reference to Berger [18]). The orbit of the Earth, E, around the Sun, S, is represented by the ellipse PAE, $\mathrm{P}$ being the Perihelion and $\mathrm{A}$ the Aphelion. Its eccentricity is given by $e=\left(a^{2}-b^{2}\right) / a$, a being the semi-major axis and $\mathrm{b}$ the semi-minor axis. Furthermore, $\gamma$ is the vernal point, WS and SS are the winter and summer solstices, respectively. They mirror their present-day locations. The vector $\boldsymbol{n}$ is perpendicular to the ecliptic and the obliquity, $\varepsilon$, is the inclination of the equator upon the ecliptic; i.e., $\varepsilon$ is equal to the angle between the Earth's axis of rotation and $\boldsymbol{n}$. The parameter $\varpi$ is the longitude of the Perihelion relative to the moving Vernal Equinox (VE) and is equal to $\xi+\psi$. The annual general precession in longitude, $\psi$, describes the absolute motion of $\gamma$ along the Earth's orbit relative to the fixed stars. The longitude of the perihelion, $\xi$, is measured from the reference vernal equinox of A.D. 1950 and describes the absolute motion of the perihelion relative to the fixed stars. For any numerical value of $\varpi, 180^{\circ}$ is subtracted for a practical purpose: observations are made from the Earth and the Sun is considered as revolving around the Earth.

geometry is indispensable and outlined here.

\subsubsection{The Sun-Earth Geometry}

The actual distance, $r$, between the Sun's center and the Earth's elliptic orbit (see Figure 2) can be expressed by the semi-major axis, $a=149.6 \times 10^{6} \mathrm{~km}$, the eccentricity, $e=0.0167$ and the true anomaly, v, i.e., the positional angle of the Earth on its orbit counted counterclockwise from the minimum of $r$ called the Perihelion,

$$
r=\frac{p}{1+e \cos v}=\frac{a\left(1-e^{2}\right)}{1+e \cos v}
$$

Here, $p=L^{2} /(m \alpha), e=\left\{1+2 E L^{2} /\left(m \alpha^{2}\right)\right\}^{1 / 2}$ and $\alpha=\gamma M m$, where $\gamma$ is the gravitational constant, $M$ is the mass of the Sun, $m$ is the mass of the Earth and $L=m r^{2} d v / d t=$ const. is the angular momentum considered as invariant with time, i.e., the angular momentum in a central field like Newton's gravity field is a con- 
TOATAL SOLAR IRRADIANCE MONITORING RESULTS: 1978 to Present

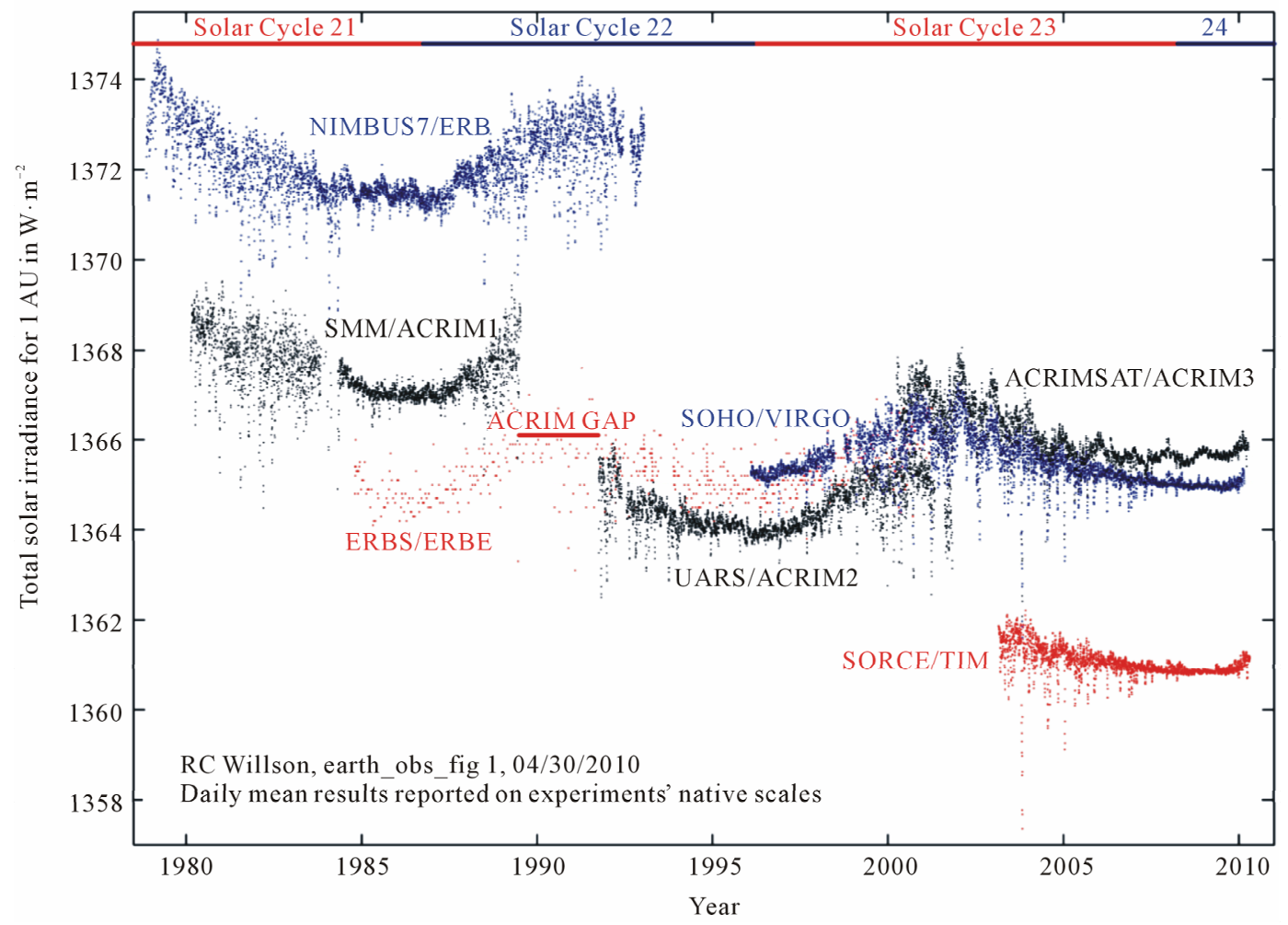

Figure 3. Satellite observations of total solar irradiance. It comprises of the observations of seven independent experiments: (a) Nimbus7/Earth Radiation Budget experiment (1978-1993); (b) Solar Maximum Mission/Active Cavity Radiometer Irradiance Monitor 1 (1980-1989); (c) Earth Radiation Budget Satellite/Earth Radiation Budget Experiment (1984-1999); (d) Upper Atmosphere Research Satellite/Active cavity Radiometer Irradiance Monitor 2 (1991-2001); (e) Solar and Heliospheric Observer/Variability of solar Irradiance and Gravity Oscillations (launched in 1996); (f) ACRIM Satellite/Active cavity Radiometer Irradiance Monitor 3 (launched in 2000) and (g) Solar Radiation and Climate Experiment/Total Irradiance Monitor (launched in 2003). The figure is based on Dr. Richard C. Willson's earth_obs_fig1, updated on April 30, 2010 (see http://www.acrim.com/).

servative quantity. The quantity $2 p$ is called the latus rectum. The Earth's elliptic orbit around the Sun, characterized by Johannes Kepler's first law that the orbit of each planet is an ellipse and the Sun is at one of the two foci, is a consequence of the state of energy in this central field expressed by $[19,20]$

$$
\frac{L^{2}}{m \alpha r}=1+\left\{1+\frac{2 E L^{2}}{m \alpha^{2}}\right\}^{1 / 2} \cos v
$$

where

$$
E=T_{\text {radial }}+U_{\text {eff }}(r)
$$

is the total energy,

$$
U_{e f f}(r)=L^{2} /\left(2 m r^{2}\right)-\alpha / r
$$

is the effective potential comprising the centrifugal potential and the gravitational potential $[19,20]$ and $T_{\text {radial }}=m(d r / d t)^{2} / 2$ is the radial kinetic energy (equal to zero in case of a circle). Obviously, Eq.2.2 leads to formula 2.1 if $p$ and $e$ are inserted. The Perihelion can be determined by setting $v=0^{\circ}$ so that $r_{p}=a(1-e)=$ $147.1 \times 10^{6} \mathrm{~km}$, achieved, for instance, on January 3 in 2011. The maximum of $r$ called the Aphelion can be determined by setting $v=180^{\circ}$. This leads to $r_{a}=a(1+$ $e)=152.1 \times 10^{6} \mathrm{~km}$; it will be achieved, for instance, on July 4 in 2011. Combining these two formulae yields $e=\left(r_{a}-r_{p}\right) /\left(r_{a}+r_{p}\right)=\left(r_{a}-r_{p}\right) /(2 a)$.

Kepler's second law reads: The radius vector drawn from the Sun's center to the center of the planet sweeps out equal areas in equal times. The period $T$ of one revolution of a planet around the Sun is given by $T=2 \mathrm{~mA} / \mathrm{L}$, where $A=\pi a b=\pi a^{2}\left(1-e^{2}\right)^{1 / 2}$ is the area of the elliptic orbit and $b=a\left(1-e^{2}\right)^{1 / 2}$ is the semi-minor axis. Thus, we may write

$$
r^{2} \frac{\mathrm{d} v}{\mathrm{~d} t}=\frac{2 \pi}{T} a^{2}\left(1-e^{2}\right)^{1 / 2}
$$


Integrating this equation yields

$$
\int_{0}^{2 \pi} r^{2} \mathrm{~d} v=\frac{2 \pi}{T} a^{2}\left(1-e^{2}\right)^{1 / 2} \int_{0}^{T} \mathrm{~d} t=2 \pi a^{2}\left(1-e^{2}\right)^{1 / 2}
$$

or [15]

$$
r_{0}^{2}=\frac{1}{2 \pi} \int_{0}^{2 \pi} r^{2} \mathrm{~d} v=a^{2}\left(1-e^{2}\right)^{1 / 2}
$$

Here, $r_{0}=a\left(1-e^{2}\right)^{1 / 4} \cong a=149.6 \times 10^{6} \mathrm{~km}$ is the average distance between the Sun's center and the Earth's orbit $(1$ Astronomic Unit $=\mathrm{AU})$. Since $b=a\left(1-e^{2}\right)^{1 / 2}=a^{1 / 2} p^{1 / 2}$, we can infer that $T^{2} / a^{3}=4 \pi^{2} m / \alpha=$ const. Therefore, we may state that the square of the time of one revolution in the orbit is proportional to the cube of the semimajor axis. This is the content of Kepler's third law. Even Kepler's three laws are based on accurate astronomical and planetary observations performed by Tycho Brahe, these laws only characterize the Earth's elliptical orbit around the Sun in an ideal manner.

Quantifying the solar insolation at the TOA as a function of latitude and time of the year requires two additional astronomical relationships, namely

$$
F=\left(\frac{r_{S}}{r}\right)^{2} F_{S}
$$

and

$$
\cos \Theta_{0}=\sin \phi \sin \delta+\cos \phi \cos \delta \cos h
$$

Here, $r_{S}=6.96 \times 10^{5} \mathrm{~km}$ is the radius of the Sun, $F$ is the solar irradiance at the TOA and $F_{S}$ denotes the solar emittance [15,21]. Furthermore, $\Theta_{0}$ is the local zenith angle of the Sun's center, $\phi$ is the latitude, $\delta$ is the solar declination angle that varies with time of the year (see also Figure 6) and $h$ is the hour angle from the local meridian (e.g., [15,21-23]).

Formula 2.8 is based on the fact that the radiant power $\left(=4 \pi r_{S}^{2} F_{S}\right)$ of the Sun is kept constant when the solar radiation is propagating through the space because of energy conservation principles in the absence of an intervening medium $[15,21,24,25]$. If we insert the mean distance, $r_{0}$, formula 2.8 can be used to define the socalled solar constant $S$ by (e.g., $[23,26]$ ).

$$
S=\left(\frac{r_{S}}{r_{0}}\right)^{2} F_{S}
$$

Frequently, a value for the solar constant close to $S \cong 1367 \mathrm{~W} \cdot \mathrm{m}^{-2}$ is recommended (e.g., $[15,27,28]$ ), but the value obtained from recent satellite observations using TIM (Total Irradiance Monitoring; launched in 2003 ) is close to $S \cong 1361 \mathrm{~W} \cdot \mathrm{m}^{-2}$ (see Figure 3). The basis for this modified value is a more reliable, improved absolute calibration [21]. Combining Formulae 2.8 and 2.10 yields

$$
F=\left(\frac{r_{0}}{r}\right)^{2} S
$$

Here, the quantity $\left(r_{0} / r\right)^{2}$ is called the orbital effect. It does not vary more than 3.5 percent (see, e.g., [15,21, 22] and Figure 4).

Formula 2.8 may also be written as

$$
\begin{aligned}
F & =\pi\left(\frac{r_{S}}{r}\right)^{2} \frac{F_{S}}{\pi}=\pi\left(\frac{r_{S}}{r}\right)^{2} \int_{0}^{\infty} B\left(v, T_{S}\right) \mathrm{d} v \\
& =\pi \int_{0}^{\infty}\left(\frac{r_{S}}{r}\right)^{2} B\left(v, T_{S}\right) \mathrm{d} v
\end{aligned}
$$

where $B\left(v, T_{S}\right)$ represents Planck's blackbody radiation formula [29], $v$ is the frequency and $T_{S} \approx 5771 \mathrm{~K}$ is the Sun's surface temperature calculated with $S=1361 \mathrm{~W} \cdot \mathrm{m}^{-2}$. Thus, to determine the monochromatic intensity of solar radiation with respect to the TOA, Planck's radiation formula has to be scaled by $\left(r_{S} / r\right)^{2}$. Sometimes, also $\pi\left(r_{S} / r\right)^{2}$ is considered for the purpose of scaling. Results for the spectral solar irradiance at the TOA and the spectral terrestrial irradiance for a temperature of $288 \mathrm{~K}$ are illustrated in Figure 5. This figure also shows the atmospheric absorption spectrum for a solar beam reaching the ground level (b) and the same for a beam reaching the temperate tropopause (c) adopted from Goody and Yung [30]. Part (a) of Figure 5 completely differs from the original twin-peak diagram of Goody and Yung. We share the argument of Gerlich and Tscheuschner $[2,4]$ that the original one is physically misleading. Areasonable version of a twin-peak diagramwas already illustrated in Fortak's [31] forty years old textbook on meteorology.

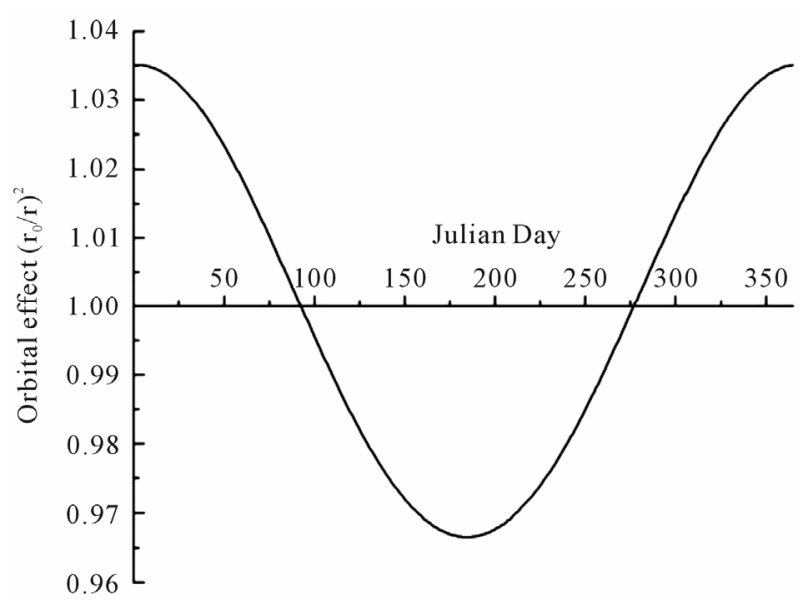

Figure 4. The orbital effect, $\left(r_{0} / r\right)^{2}$, as a function of the Julian Day. 

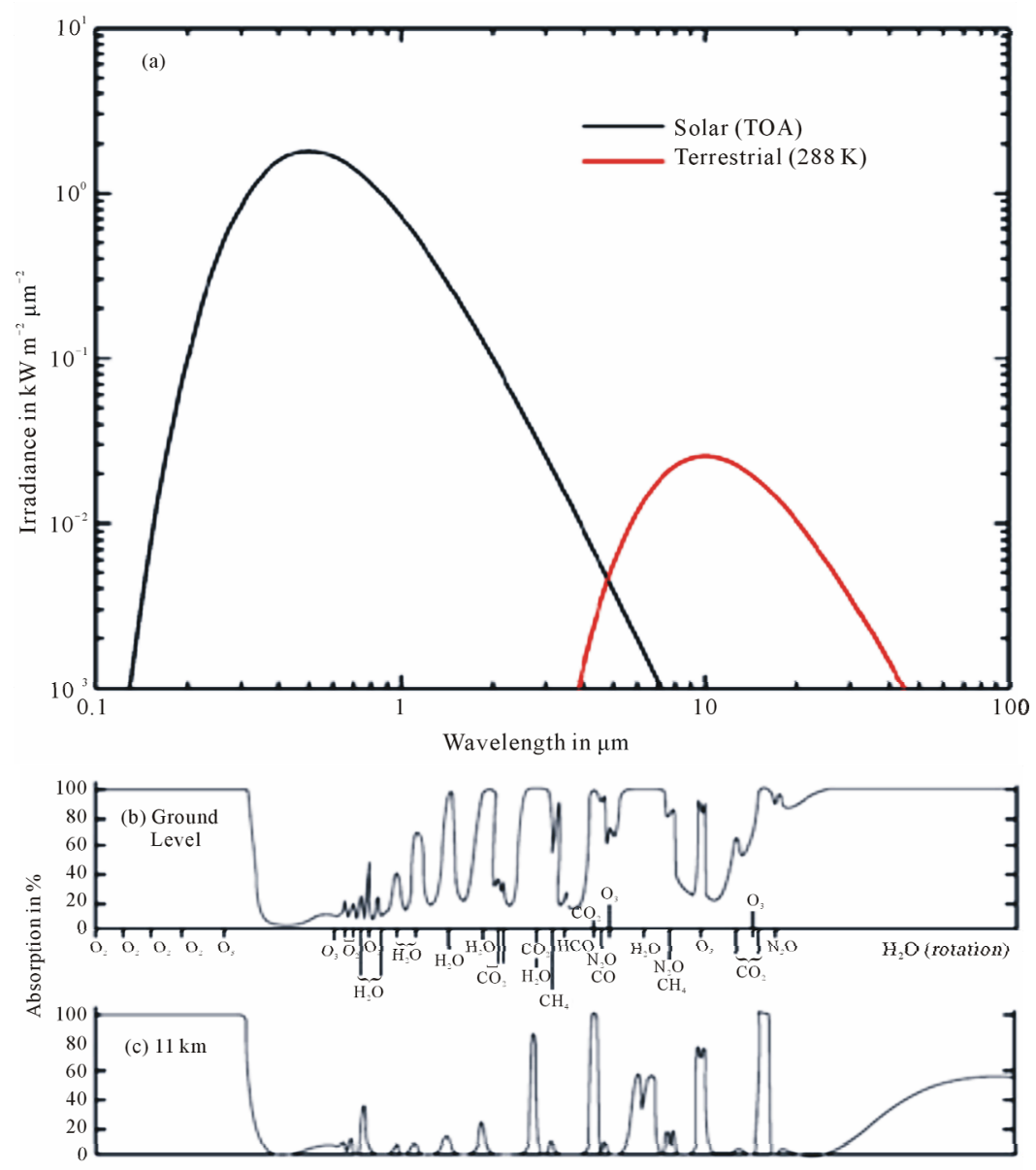

Figure 5. (a) Spectral solar irradiance the top of the atmosphere (a Sun's surface temperature of $5771 \mathrm{~K}$ is assumed) and spectral terrestrial irradiance for an Earth's surface temperature of $288 \mathrm{~K}$. Also shown: (b) Atmospheric absorption spectrum for a solar beam reaching the ground level and (c) the same for a beam reaching the temperate tropopause (adopted from Goody and Yung [30]).

Formula 2.9 is based on the rules of spherical trigonometry. It requires the solar declination angle that is related to

$$
\sin \delta=\sin \varepsilon \sin (v+\varpi)=\sin \varepsilon \sin \lambda
$$

where $\varepsilon$ is, again, the oblique angle and $\lambda=v+\varpi$ is the true longitude of the Earth counted counterclockwise from the vernal equinox (e.g., $[15,17,23]$ ). Since the latitude is related to the zenith angle by $\phi=\pi / 2-\theta$, Formula 2.9 may also be written as $\cos \Theta_{0}=\cos \theta \sin \delta+\sin \theta \cos \delta \cos h$. Note that $\theta$ is ranging from zero to $\pi, \delta$ from $23^{\circ} 27^{\prime} \mathrm{S}$ (Tropic of Capricorn; $\lambda=3 \pi / 2$ ) to $23^{\circ} 27 \mathrm{~N}$ (Tropic of Cancer; $\lambda=\pi / 2)$ and $h$ from $-H$ to $H$, where $H$ represents the half-day, i.e., from sunrise to solar noon or solar noon to sunset. It can be deduced from Eq.2.9 by setting $\Theta_{0}=\pi / 2$ (invalid at the poles) leading to $\cos H=-\tan \phi \tan \delta \quad$ (e.g., $[15,22,23]$ ).
Based on this information we can calculate the solar insolation that is defined as the flux of solar radiation per unit of horizontal area for a given location $[15,32]$. Thus, the daily solar insolation at the TOA, $Q$, is given by (e.g., $[15,17,22,24,32])$.

$$
Q=\int_{t_{r}}^{t_{s}} F \cos \Theta_{0} \mathrm{~d} t=\int_{t_{r}}^{t_{s}}\left(\frac{r_{0}}{r}\right)^{2} S \cos \Theta_{0} \mathrm{~d} t
$$

Here, $t$ is time, where $t_{r}$ and $t_{s}$ correspond to sunrise and sunset, respectively. If we acknowledge that the variation of $S$ and $r$ during one day can be neglected, we will obtain

$$
\begin{aligned}
Q & =\left(\frac{r_{0}}{r}\right)^{2} S \int_{t_{r}}^{t_{s}} \cos \Theta_{0} \mathrm{~d} t \\
& =\left(\frac{r_{0}}{r}\right)^{2} S \int_{t_{r}}^{t_{s}}(\cos \theta \sin \delta+\sin \theta \cos \delta \cos h) \mathrm{d} t
\end{aligned}
$$


Since the angular velocity of the Earth is given by $\Omega=\mathrm{d} h / \mathrm{d} t=2 \pi \mathrm{rad} /$ day, Eq.2.15 may be written as $[10$, $15,17,21]$.

$$
\begin{aligned}
Q & =\left(\frac{r_{0}}{r}\right)^{2} \frac{S}{\Omega} \int_{-H}^{H}(\cos \theta \sin \delta+\sin \theta \cos \delta \cos h) \mathrm{d} h \\
& =\left(\frac{r_{0}}{r}\right)^{2} \frac{S}{\pi}(H \cos \theta \sin \delta+\sin \theta \cos \delta \sin H)
\end{aligned}
$$

According to this formula the daily solar insolation only depends of two variables, namely the latitude and time of the year. This dependency is illustrated in Figure 6. In accord with Haltiner and Martin [24] we may deduce from this figure for the current values of $\left(r_{0} / r\right)^{2}$ and $\delta$ that 1) the time-latitude maximum of solar insolation occurs at the summer solstice at the pole because of the long solar day of 24 hours, where a secondary maximum on this date occurs near the latitude of $35^{\circ}$ in the summer hemisphere and 2) for each latitude, the southern hemisphere summer (winter) insolation is greater (less) than that of the corresponding northern hemisphere latitude in its summer (winter). Its distribution depends on the latitude, but is independent of longitude. As illustrated in that figure, there is a slight asymmetry between the northern and the southern hemisphere. This is due to the variation in the Sun-Earth distance when the Earth revolves around the Sun. However, if Eq.2.14 is integrated over all days of a year, the annual insolations are equal at corresponding latitudes of each hemisphere.

As shown before, the orbital effect, $\left(r_{0} / r\right)^{2}$, is affected by the eccentricity, $e$ and the true anomaly, $v$. According to Formula 2.13, $\delta$ dependson $\varepsilon, v$ and $\varpi$. Thus, on long-term scales of many thousands of years (expressed in kyr) we have to pay attention to Milankovitch's [33] astronomical theory of climatic variations that ranks as the most important achievement in the theory of climate in the $20^{\text {th }}$ century [10]. (In accord with Berger [18], we denote such long-term changes as climate variations.) Milankovitch's astronomical theory is related to the change of the eccentricity and the obliquity (axial tilting) and to precession and nutation phenomena owing to the perturbations that Sun, Moon and the principal planets of our solar system exert on the Earth's orbit (e.g., $[10,15,17,18,34,35])$ ideally characterized by Eqs.2.1 to 2.7. It plays a substantial role in time series analysis of paleoclimate records (see, e.g., $[35,36])$. Because of these astronomical phenomena, briefly described here, the solar insolation at the TOA will vary periodically during such long-term periods.

As the Earth is not a sphere, but an oblate spheroid and because of the obliquity, i.e., the tilt of the Earth's rotational axis with respect to the normal vector, $\boldsymbol{n}$, of

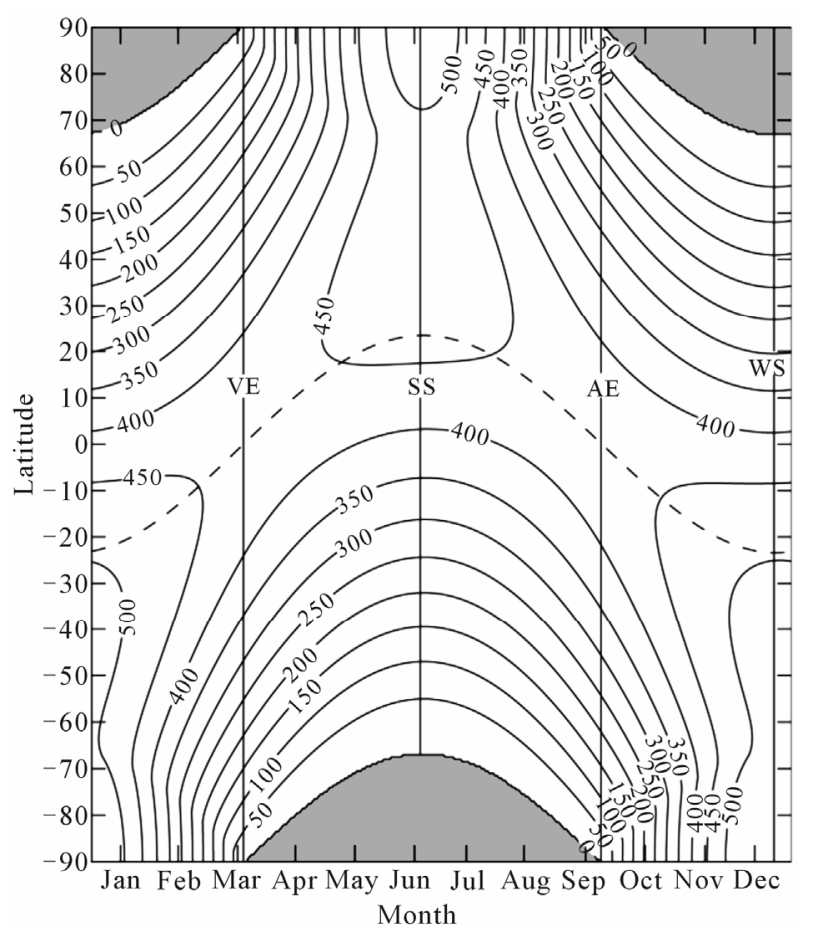

Figure 6. Daily solar insolation $\left(86,400 \mathrm{~J} \cdot \mathrm{m}^{2}\right)$ at the top of the atmosphere as a function of latitude and day of year using a solar constant of $1366 \mathrm{~W} \cdot \mathrm{m}^{-2}$. The shaded areas denote zero insolation. The positions of vernal equinox (VE), summer solstice (SS), autumnal equinox (AE) and winter solstice (WS) are indicated with solid vertical lines. Solar declination is shown with a dashed line (adopted from Liou [15], slightly modified by $\mathrm{Fu}[104])$.

the plane of the ecliptic pointing to the ecliptic pole (see Figure 2), mainly the gravitational forces of the Sun and the Moon cause a torque on it leading to a small temporal change in the angular momentum, i.e., the assumption that the angular momentum is a conservative quantity used in Subsection 2.1.1 is not exactly fulfilled.This torque tries to aim the Earth's rotational axis parallel to $\boldsymbol{n}$ $[20,37]$. Like in case of a spinning toy top on which a torque is acting the Earth's rotational axis traces out a cone (see Figure 2) in a cycle of about $25.7 \mathrm{kyr}$. It is customarily called lunisolar precession. Since Sun and Moon change their positions relative to each other their gravitational forces also cause a nutation of the Earth's rotational axis which, however, is much smaller in magnitude than the lunisolar precession (for more details about precession/nutation variables, see [38-40]). Note that, according to the recommendation of the International Astronomic Union, Division I Working Group on Precession and the Ecliptic published by Hilton et al. [40], lunisolar precession and planetary precession have to be replaced by precession of the equator and precession of the ecliptic for general use. Both precession phenomena are still subsumed under the notion "general 
precession".

A closed elliptic orbit as ideally characterized by Eqs. 2.1 to 2.7 requires that the gravitational potential reciprocally depends on $r$ (see the $2^{\text {nd }}$ term on the right-hand side of Eq.2.4). Deviations from that owing to the perturbations of the gravity field by other planets lead to an open orbit of a rosette-like shape (see Figure 7). It seems that the Earth's orbit moves around the Sun resulting in a precession of the Perihelion (see Figure 7). The combination of the general precession and the precession of the Perihelion is called the climatic precession and the related parameter $e \sin \varpi$ is called the climatic precession parameter. A combined effect of these precession phenomena is sketched in Figure 8. Today, the North Pole tilts away from the Sun at Perihelion (southern summer). On the contrary, the North Pole tilted towards the Sun at Perihelion (northern summer) 11,000 years ago.

Results of computations performed by Berger and Loutre [41] to reconstruct the astronomical parameters over the last 5000 kyr (only the last 500 kyr are illustrated in Figure 9) suggest that the eccentricity, $e$, varies between 0 and 0.057 mainly associated with periods of about 95 kyr, 124 kyr and 410 kyr (see Figure 10) and that the obliquity, $\varepsilon$, varies between $22^{\circ}$ and $24^{\circ} 30^{\prime}$ with a dominant period of about $41 \mathrm{kyr}$ (see Figure 10). The revolution of the vernal point $\gamma$ relative to the moving perihelion (which is related to climatic precession [18]) is mainly associated with periods of about 19 kyr, $22 \mathrm{kyr}$ and $24 \mathrm{kyr}$ (see Figure 10). Whereas relative to the fixed perihelion of reference, the quasi-period is $25.7 \mathrm{kyr}$, i.e., the well known astronomical precession of the equinoxes [18] mentioned before. Figure 9 also shows the periodically variation of the mid-month insolation for the latitudes $65^{\circ} \mathrm{N}$, July and $65^{\circ} \mathrm{S}$, January, where the former is ranging between $388 \mathrm{~W} \cdot \mathrm{m}^{-2}$ and 502 $\mathrm{W} \cdot \mathrm{m}^{-2}$ and the latter is varying between $388 \mathrm{~W} \cdot \mathrm{m}^{-2}$ and $498 \mathrm{~W} \cdot \mathrm{m}^{-2}$. These insolation variations are associated with main periods of about $19 \mathrm{kyr}, 22 \mathrm{kyr}, 24 \mathrm{kyr}$ and 41 kyr (see Figure 10). As reported by Lindzen [35], Milankovitch stressed the importance of summer insolation at high latitudes for the melting of winter snow accumulation. Berger et al. [42] and Loutre et al. [16], however, suggest that insolation at latitudes and/or time of the year other than the classical " $65^{\circ} \mathrm{N}$ latitude in summer" could also be used for comparison with proxy records.

\subsubsection{The Energy Conversion in the Atmosphere}

A notable portion of the solar radiation penetrating into the atmosphere $\left(340 \mathrm{~W} \cdot \mathrm{m}^{-2}\right.$ on global average $)$ is absorbed in the ultraviolet and the visible range as well as in the near infrared range by various gaseous and particulate constituents of the atmosphere. Especially the

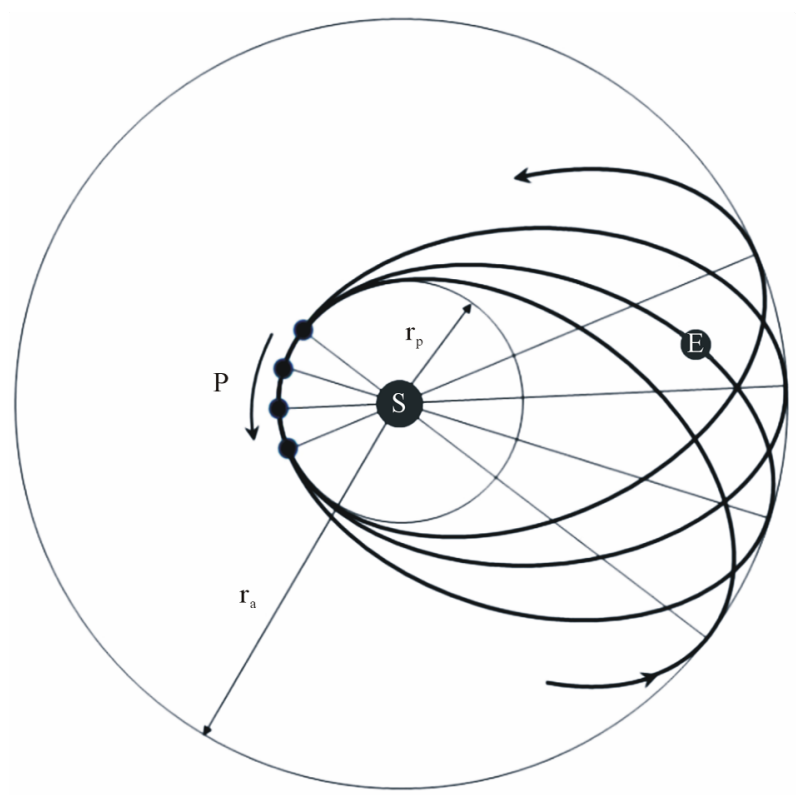

Figure 7. Open orbit of a rosette-like shape and the precession of the Perihelion. Here, $r_{p}$ is the radius of the circle on which the Perihelion is advancing by an angle of $\Delta \vartheta$ and $r_{a}$ is the radius on which the Aphelion is moving forward by $\Delta \vartheta$ (with reference to Mittelstaedt [19]).
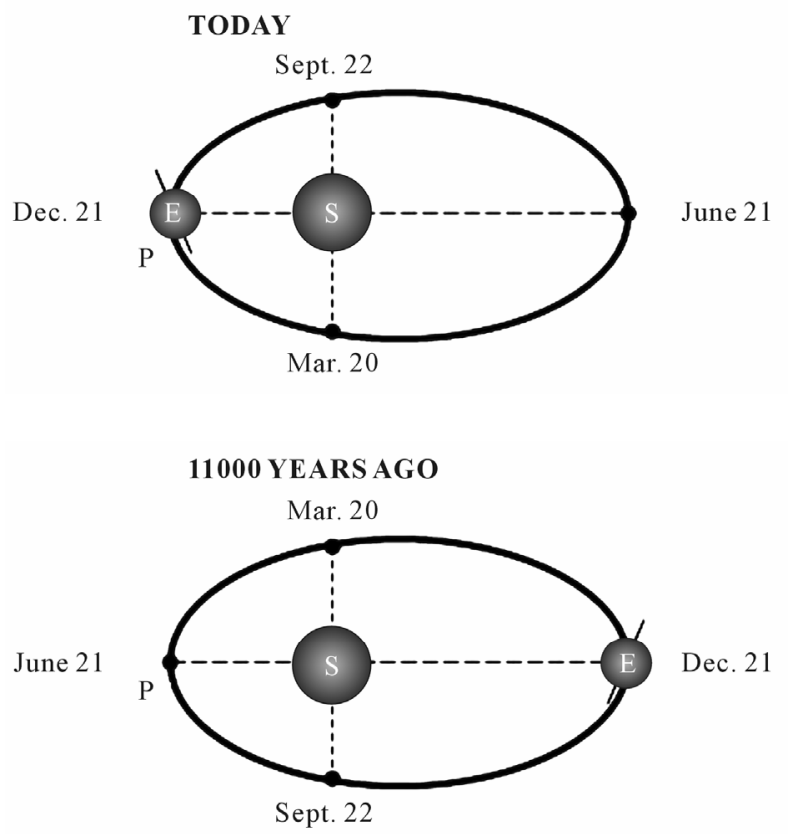

Figure 8. Combined effect of the precession phenomena (with reference to Crowley and North [36]). The symbol P stands for the Perihelion.

absorption of solar radiation by molecular oxygen $\left(\mathrm{O}_{2}\right)$ and ozone $\left(\mathrm{O}_{3}\right)$, i.e., the $\mathrm{O}_{2}$ Schumann-Runge continuum (130 - $175 \mathrm{~nm}$; principally located in the thermosphere), the $\mathrm{O}_{2}$ Schumann-Runge bands (175 - $200 \mathrm{~nm}$; prince- 


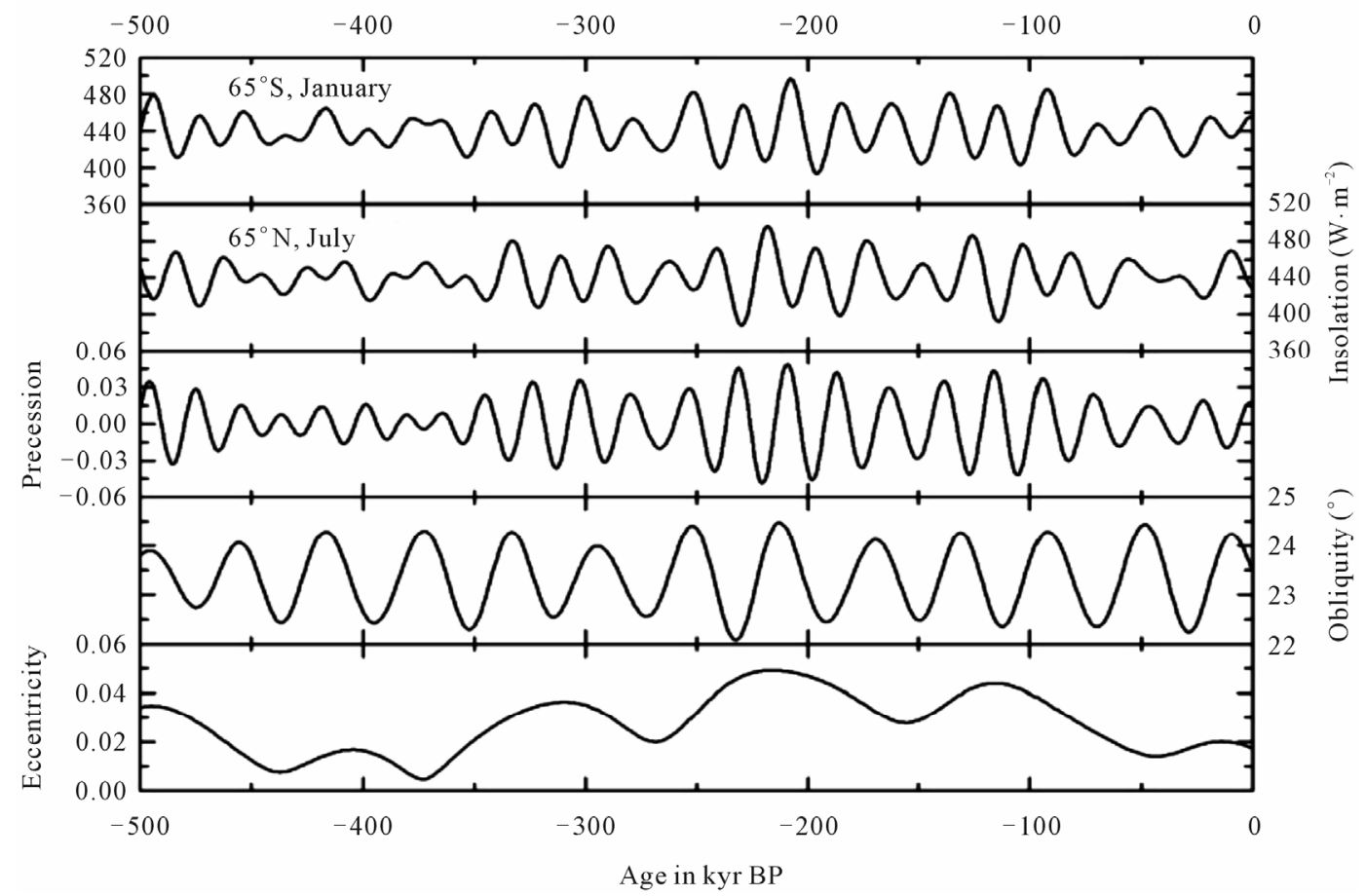

Figure 9. Long-term variations of eccentricity, obliquity, climatic precession (characterized by the climatic precession parameter, $e$ sin $\varpi$ ), the mid-month insolation for the latitudes $65^{\circ} \mathrm{N}$, July and $65^{\circ} \mathrm{S}$, January, from $500 \mathrm{kyr}$ BP to present (1950.0 A.D.). Note that a solar constant of $\mathrm{S}=1360 \mathrm{~W} \cdot \mathrm{m}^{-2}$ was considered (all data are taken from Berger and Loutre $[41,105])$.
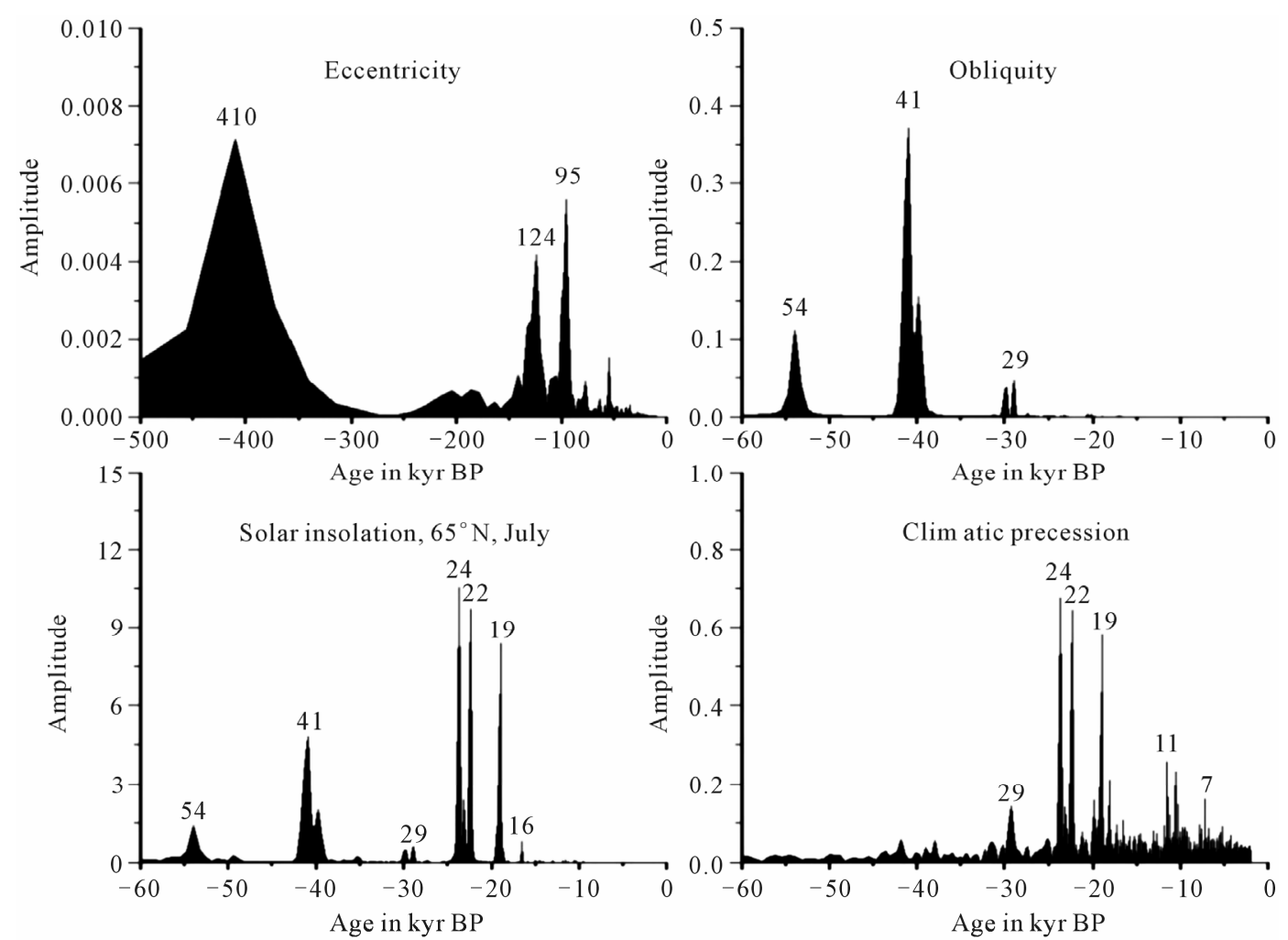

Figure 10. Dominant periods for eccentricity, obliquity, climatic precession and mid-July insolation at a latitude of $65^{\circ} \mathrm{N}$ deter-mined by FFT (Welch) on the basis of the orbital data of Berger and Loutre $[41,105]$. 
pally located in the mesosphere), the $\mathrm{O}_{2}$ Herzberg continuum (200 - $242 \mathrm{~nm}$; principally located in the stratosphere), the $\mathrm{O}_{3}$ Hartley bands (200 - $310 \mathrm{~nm}$; principally located in the stratosphere), the $\mathrm{O}_{3}$ Huggins bands (310 $400 \mathrm{~nm}$; principally located in the stratosphere and troposphere) and the $\mathrm{O}_{3}$ Chappius bands (400 - $850 \mathrm{~nm}$; principally located in the troposphere) [43], serves to heat the atmosphere directly. As illustrated in Figure 5, water vapor $\left(\mathrm{H}_{2} \mathrm{O}\right)$ and $\mathrm{O}_{2}$ are also active in the visible and near infrared range; nitrogen dioxide $\left(\mathrm{NO}_{2}\right)$ is active in the visible range, too. According to Trenberth et al. [44] the direct heating of the atmosphere owing to the absorption of solar radiation by atmospheric constituents consumed 23 percent (or $78 \mathrm{~W} \cdot \mathrm{m}^{-2}$ ), on global average, of the solar radiation at the TOA (see Table 2 and Figure 15).

Furthermore, a considerable portion of the solar radiation at the TOA is back-scattered by molecules (Rayleigh scattering), cloud and aerosol particles (Lorenz-Mie scattering), where a notable amount of solar radiation reaching the Earth's surface is also reflected. These processes contribute to a planetary albedo of about 30 percent that results in $102 \mathrm{~W} \cdot \mathrm{m}^{-2}$, on global average. Thus, only the remainder of about 70 percent (or $238 \mathrm{~W} \cdot \mathrm{m}^{-2}$ ) of solar radiation, on global average, serves to heat the Earth-atmosphere system (see Table 2).

To investigate the effects of the underlying surface of ocean and land on the atmosphere to the inclination as Alexander von Humboldt suggested, we have to consider the solar insolation at the Earth's surface. It is absorbed and reflected, respectively, either by the soil-vegetation systems and the water systems of landscapes or by the ocean depending on the location considered (expressed by longitude and latitude) and time of the year. The absorbed solar radiation is converted into heat and, hence, contributes to the warming of the soil and water layers adjacent to the Earth's surface, respectively. These respective layers also exchange energy with the atmospheric boundary layer (ABL) characterized by the flux densities (simply denoted as fluxes hereafter) of sensible and latent heat. These fluxes serve, on global average, to heat the atmosphere from below (see Table 2) and cause convective transports of energy and mass in higher regions of the troposphere. Especially the release of latent heat in the troposphere while water vapor undergoes phase changes to form water drops and/or ice particles

Table 2. Summary of the Earth's energy budget estimates (with respect to Kiehl and Trenberth [95]). The sources [24,44] and [31] are inserted and source [15] is updated.

\begin{tabular}{|c|c|c|c|c|c|c|}
\hline \multicolumn{4}{|c|}{ Earth's surface } & \multirow{2}{*}{$\begin{array}{c}\text { Atmosphere } \\
A_{a}\end{array}$} & \multirow{2}{*}{$\frac{\text { TOA }}{\alpha_{E}}$} & \multirow{2}{*}{ Source } \\
\hline$\left(1-\alpha_{E}-A_{a}\right) S / 4\left(\mathrm{~W} \cdot \mathrm{m}^{-2}\right)$ & $\Delta R_{L \uparrow}\left(\mathrm{W} \cdot \mathrm{m}^{-2}\right)$ & $H\left(\mathrm{~W} \cdot \mathrm{m}^{-2}\right)$ & $E\left(\mathrm{~W} \cdot \mathrm{m}^{-2}\right)$ & & & \\
\hline 145 & 47 & 20 & 78 & 0.22 & 0.35 & [24] \\
\hline 164 & 70 & 17 & 77 & 0.17 & 0.36 & {$[31]$} \\
\hline 174 & 72 & 24 & 79 & 0.19 & 0.30 & {$[96]$} \\
\hline 157 & 52 & 17 & 88 & 0.24 & 0.30 & {$[97]$} \\
\hline 174 & 68 & 27 & 79 & 0.19 & 0.30 & [98] \\
\hline 171 & 72 & 17 & 82 & 0.20 & 0.30 & {$[72]$} \\
\hline 169 & 63 & 16 & 90 & 0.20 & 0.31 & [99] \\
\hline 154 & 55 & 17 & 82 & 0.25 & 0.30 & {$[100]$} \\
\hline 161 & 66 & 26 & 69 & 0.23 & 0.30 & {$[15]$} \\
\hline 171 & 68 & 21 & 82 & 0.20 & 0.30 & [32] \\
\hline 157 & 51 & 24 & 82 & 0.23 & 0.31 & [101] \\
\hline 171 & 68 & 24 & 79 & 0.20 & 0.30 & [102] \\
\hline 168 & 66 & 24 & 78 & 0.20 & 0.31 & [95] \\
\hline 165 & 46 & - & - & 0.19 & 0.33 & [103] \\
\hline 161 & 63 & 17 & 80 & 0.23 & 0.30 & {$[44]$} \\
\hline
\end{tabular}


by cloud microphysical processes mainly contributes to establish and perpetuate atmospheric circulation systems and cycles of different spatial and temporal scales, respectively (see also Figure 11), where also the Earth's rotation plays a notable role. The Hadley cells at both sides of the Intertropical Convergence Zone (ITCZ), for instance, are essential for maintaining the general circulation in the atmosphere [45]. They are perpetuated by the release of latent heat in the so-called hot towers embedded in mesoscale convective systems, which are an order of magnitude greater in area than the hot tower updraft [46]. These hot towers in which notably diluted warm moist air of the ABL is transported upward even penetrates the tropopause and the lower stratosphere [45, 47]. As argued by Lindzen and Pan [35,48], orbital variations can greatly influence the intensity of the Hadley circulation, i.e., orbital variations can also affect the general circulation in the atmosphere and the related heat transfer on the planetary scale.

As the absorption of solar radiation by atmospheric constituents and the exchange of energy between the soil and/or water layers adjacent to the Earth's surface and the atmosphere by the fluxes of sensible and latent heat already serve to heat the atmosphere (of about 74 per- cent or $175 \mathrm{~W} \cdot \mathrm{m}^{-2}$ of the energetically relevant solar radiation, on global average, see Table 2), we have to expect that those atmospheric constituents, which are able to emit and absorb infrared (IR) radiation (usually in finite spectral ranges), will emit energy in the IR range in all directions. The amount of this IR radiation depends on the temperature of these constituents. From this point of view it is indispensable to consider the down-welling IR radiation reaching the Earth's surface, where most of it is absorbed.

The soil and/or water layers adjacent to the Earth's surface also emit IR radiation depending on the surface temperature. A notable portion of this IR radiation is absorbed by atmospheric constituents and emitted in all directions, too. A smaller one is propagating through the atmosphere where the extinction by intervening constituents is small. Such a spectral region is the so-called atmospheric window ranging from $8.3 \mu \mathrm{m}$ to $12.5 \mu \mathrm{m}$ (e.g., $[15,25,27,49])$ that corresponds to spectroscopic wave numbers ranging from $1250 \mathrm{~cm}^{-1}$ to $800 \mathrm{~cm}^{-1}$. It only contains the $9.6 \mu \mathrm{m}$-band of ozone. The spectral region of the atmospheric window ranging from $10 \mu \mathrm{m}$ to $12.5 \mu \mathrm{m}$ is the most common band for meteorological satellites because it is relatively transparent to radiation

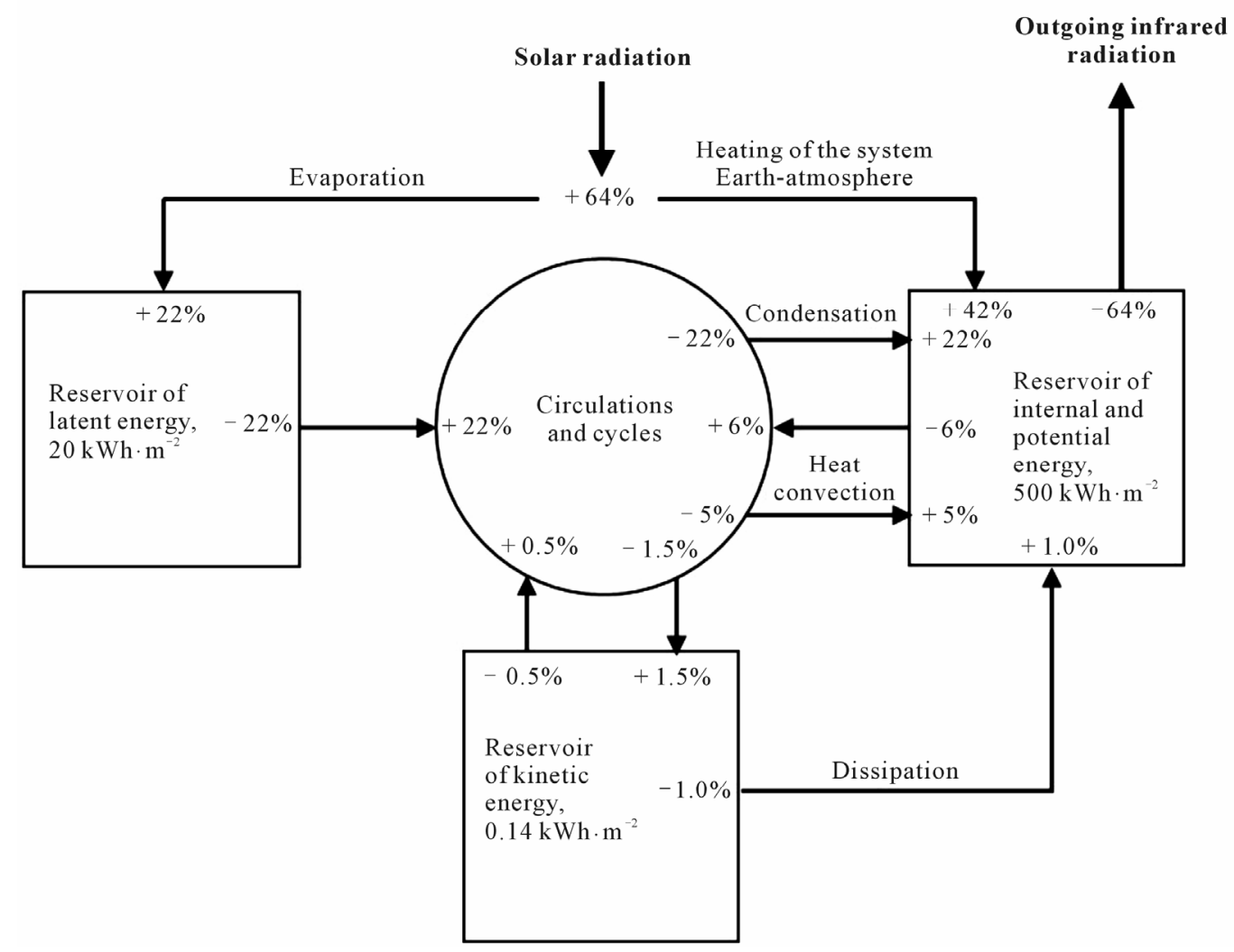

Figure 11. The main energy reservoirs of the system Earth-atmosphere and the energy fluxes (global annual means) between them which are linked to the existence of circulations and cycles within this system (adopted from Fortak [31]). 
up-welling from the earth's surface [49].

\subsubsection{The Energy Conversion at the Earth's Surface}

If we consider only bare soil ${ }^{1}$ for the purpose of simplification (it will play a prominent role in Section 3), the energy-flux balance at the Earth's surface for a given location (characterized, for instance, by the zenith angle, $\theta$ and the and azimuthal angle, $\varphi$ ) reads (only the components normal to the horizontal surface element play a role)

$$
\begin{aligned}
& R_{S \downarrow}\left(\Theta_{0}, \theta, \varphi\right)\left(1-\alpha_{S}\left(\Theta_{0}, \theta, \varphi\right)\right) \\
& +\varepsilon(\theta, \varphi) R_{L \downarrow}(\theta, \varphi)-\varepsilon(\theta, \varphi) \sigma T_{s}^{4}(\theta, \varphi) \\
& -L_{v}\left(T_{s}, \theta, \varphi\right) Q(\theta, \varphi)-H(\theta, \varphi)+G(\theta, \varphi)=0 .
\end{aligned}
$$

Here, $R_{S \downarrow}\left(\Theta_{0}, \theta, \varphi\right)$ is the global (direct plus diffusive solar) radiation, $\Theta_{0}=\Theta_{0}(\theta, \varphi)$ is local zenith angle of the Sun's center, $\alpha_{S}\left(\Theta_{0}, \theta, \varphi\right)$ is the albedo in the short-wave range, $R_{L \downarrow}(\theta, \varphi)$ is the down-welling long-wave radiation, $\varepsilon(\theta, \varphi)=1-\alpha_{L}(\theta, \varphi)$ is the relative emissivity assumed to be equal to the absorptivity, $\alpha_{L}(\theta, \varphi)$ is the albedo of the long-wave range and $T_{s}(\theta, \varphi)$ is the surface temperature. The quantities $Q(\theta, \varphi)$ and $H(\theta, \varphi)$ are the fluxes of water vapor and sensible heat within the atmosphere caused by mainly molecular effects in the immediate vicinity of the Earth's surface and by turbulent effects in the layers above. These fluxes are usually not directly measured, i.e., they have to be computed on the basis of mean quantities derived from observations. Under horizontally homogeneous and steady-state conditions these fluxes can be parameterized by [65].

$$
Q(\theta, \varphi)=-\left.\bar{\rho} C_{q}\left(\widehat{u_{R}}-\widehat{u_{s}}\right)\left(\widehat{q_{R}}-\widehat{q_{s}}\right)\right|_{\theta, \varphi}=\text { const }
$$

and

$$
H(\theta, \varphi)=-\left.\bar{\rho} c_{p} C_{h}\left(\widehat{u_{R}}-\widehat{u_{s}}\right)\left(\widehat{\Theta_{R}}-\widehat{T_{s}}\right)\right|_{\theta, \varphi}=\text { const } .
$$

Here, $\bar{\rho}$ is the mean air density, $c_{p}$ is the specific heat at constant pressure, $C_{h}$ and $C_{q}$ are the transfer coefficients for sensible heat and water vapor, respectively. Furthermore, $\widehat{u_{R}}$ and $\widehat{u_{s}}$ are the mean values of the wind speed at $z_{R}$, the outer edge of the atmospheric surface layer (subscript R) and at the Earth's surface (subscript $\mathrm{s}$ ), where in case of rigid walls the latter is equal to zero, $\widehat{\Theta_{R}}$ is the mean potential temperature at $z_{R}, \widehat{T}_{s}$ is the mean absolute temperature at the surface, where usually $\widehat{T_{s}} \cong T_{s}$ is assumed and $\widehat{q_{r}}$ and

${ }^{1}$ The inclusion of a vegetation canopy has been discussed, for instance by Deardorff [50], McCumber [51,52], Meyers and Paw U [53,54], Sellers et al. [55], Braud et al. [56], Kramm et al. [57,58], Ziemann[59] Su et al. [60], Pyles et al. [61,62] and Mölders et al. [63,64]. $\widehat{q_{s}}$ are the corresponding values of the specific humidity, respectively. As expressed by these equations, these fluxes at a given location are related to differences of temperature, humidity and wind speed between a certain reference height, $z_{R}$ and the Earth's surface.Moreover, $L_{v}\left(T_{s}, \theta, \varphi\right)$ is the specific heat of phase transition (e.g., vaporization, sublimation) and $G(\theta, \varphi)$ is the soil heat flux. Since reflectivity and relative emissivity depend on the wavelength, the surface properties $\alpha_{S}\left(\Theta_{0}, \theta, \varphi\right)$, $\alpha_{L}\left(\Theta_{0}, \theta, \varphi\right)$ and $\varepsilon(\theta, \varphi)$ represent integral values. Note that the use of the power law of Stefan [66] and Boltzmann [67] requires a local formulation because its derivation is not only based on the integration of Planck's [29] blackbody radiation law, for instance, over all frequencies (from zero to infinity), but also on the integration of the isotropic emission of radiant energy by a small spot of the surface (like a hole in the opaque walls of a cavity) over the adjacent half space (e.g., [15, 68]). The latter corresponds to the integration over a vector field. We may assume that the condition of the local thermodynamic equilibrium is fulfilled (usually up to $60 \mathrm{~km}$ or so above the Earth's surface). Furthermore, a flux is counted positive when it is directed to the Earth's surface.

The water vapor flux, $Q(\theta, \varphi)$, that occurs in this energy-flux balance is related to the water-flux balance given by

$$
P(\theta, \varphi)-R_{O}(\theta, \varphi)-Q(\theta, \varphi)-I(\theta, \varphi)=0
$$

Here, $P(\theta, \varphi)$ is the precipitation, $R_{O}(\theta, \varphi)$ is the surface runoff and $I(\theta, \varphi)$ is the infiltration. This coupled set of simple equations already documents the difficulty and challenge related to the prediction of second kind. The net radiation,

$$
\begin{aligned}
R_{N}\left(\Theta_{0}, \theta, \varphi\right) & =R_{S \downarrow}\left(\Theta_{0}, \theta, \varphi\right)\left(1-\alpha_{S}\left(\Theta_{0}, \theta, \varphi\right)\right) \\
& +\varepsilon(\theta, \varphi) R_{L \downarrow}(\theta, \varphi)-\varepsilon(\theta, \varphi) \sigma T_{s}^{4}(\theta, \varphi),
\end{aligned}
$$

is not only related to the fluxes of sensible heat and water vapor and the soil heat flux, but also on the surface runoff, infiltration and precipitation caused by cloud microphysical processes. These cloud microphysical processes also affect the radiation transfer of both solar and IR radiation as well as the surface properties like the integral values of the shortwave albedo and the relative emissivity. Note that the difference

$$
\Delta R_{L \uparrow}(\theta, \varphi)=\varepsilon(\theta, \varphi) \sigma T_{s}^{4}(\theta, \varphi)-\varepsilon(\theta, \varphi) R_{L \downarrow}(\theta, \varphi)
$$

is also called the net radiation in the infrared range. This difference is usually positive (see, e.g., Section 5 of Kramm and Dlugi [21]). 
In comparison with bare soil, the determination of the temperature at water surfaces is more complex because 1) a fraction of the incident solar radiation may penetrate into the water up to a considerable depth without significant absorption and 2) at both sides of the atmosphere-water interface the transition of a viscous transfer to a fully turbulent transfer has to be considered (see Figure 12). Also the exchange of sensible and latent heat and infrared radiation between the ocean and the atmosphere can only be determined for a given location characterized in a similar manner as before, i.e. by $\theta$ and $\varphi$. Note that the local flux quantities like $Q(\theta, \varphi)$, $H(\theta, \varphi), G(\theta, \varphi)$ and $\Delta R_{L \uparrow}(\theta, \varphi)$ are required to calculate global averages of these fluxes, but not global averages of respective values of temperature and humidity.

\subsubsection{The Scope of the Physical Climatology}

On the basis of the Subsections 2.1.1 to 2.1.3 we may state that studying 1) the input of solar energy into the system Earth-atmosphere, 2) the temporal and spatial distribution of this energy in the atmosphere and the oceans by radiative transfer processes, circulation systems and cycles, governed by fundamentalgeophysical fluid dynamic processes, 3) the absorption of solar irradiance in the underlying soil, 4) the exchange of energy between the Earth's surface and the atmosphere by the fluxes of sensible and latent heat and the infrared net radiation and 5) the long-term coinage of the boundary conditions of the respective climate system under study is the scope of the physical climatology.

\subsection{The Scope of the Statistical Climatology}

The scope of the statistical climatology is the statistical description of weather states over long-term periods of, at least, thirty years to characterize the climate of locations, regions or even climate zones by mean values and higher statistical moments like variance (or its positive square root, called the standard deviation), skewness and kurtosis. Since weather states can only be related to locations and regions at a given time (interval), but not to a global scale, even from this point of view, we have to acknowledge that the notion "global climate" is a contradiction in terms.

The difference between weather and climate is illustrated in Figure 13. Black curves always characterize the climate of a location or region for the $n^{\text {th }}$ climate period (usually 30 years) at the hand of a frequency distribution of an observed quantity of the corresponding weather events (green dots) assumed, for the purpose of simplification, to be a normally (Gaussian) distributed random variable. This probability density function (PDF) of the $n^{\text {th }}$ climate period is characterized by the mean value $\mu_{n}$

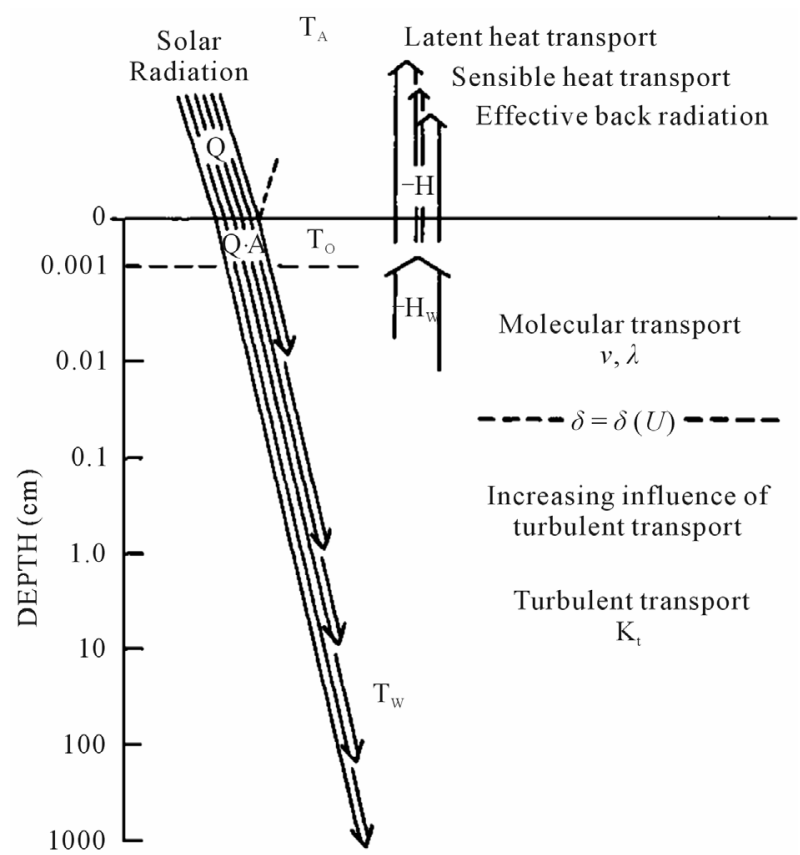

Figure 12. Schematic diagram of the heat flow at the air-sea interface (adopted from Hasse [106]). Note that $Q$ is the incident solar radiation an a horizontal surface, $A$ is the fraction of this radiation penetrating into the water, $\delta=\delta(U)$ (depending on the horizontal wind speed $U$ ) is the depth of the water layer mainly governed by molecular effect, $T_{0}$ is the representative temperature of the water skin, $T_{W}$ is the water temperature and $H_{W}$ is the heat flux within the water. Furthermore, $K_{t}$ is the eddy diffusivity and $v$ and $\lambda$ are the kinematic viscosity and the molecular diffusivity of water, respectively.

and the standard deviation $\sigma_{n}$. Red curves characterize the $(n+i)^{\text {th }}$ climate period, $i= \pm 1, \pm 2, \cdots$, where, again, a similar shape of the PDF is assumed. In case of a change from the $n^{\text {th }}$ climate period to the $(n+i)^{\text {th }}$ climate, the mean values, $\mu_{n}$ and $\mu_{n i}$ and/or the standard deviations, $\sigma_{n}$ and $\sigma_{n i}$, can differ from each other indicating, for instance, a change in the occurrence of extreme weather events. Even the shape of the PDF may change with time. Harmel et al. [69], for instance, reported that the results of their analysis indicate that measured daily maximum and minimum temperature are not generally normally distributed in each month but are skewed. They continued that 1) this finding contradicts a standard assumption in most weather generators that temperature data are normally distributed and 2) this violation does not affect reproduction of monthly means and standard deviations but does result in simulated monthly temperature populations that do not represent the distribution of measured data. As any asymmetry in PDF is already mirrored by the odd central moment of lowest-order, one may use the third central moment (or in a further step the skewness) to characterize such an asymmetry. Thus, long-term periods are indispensable 

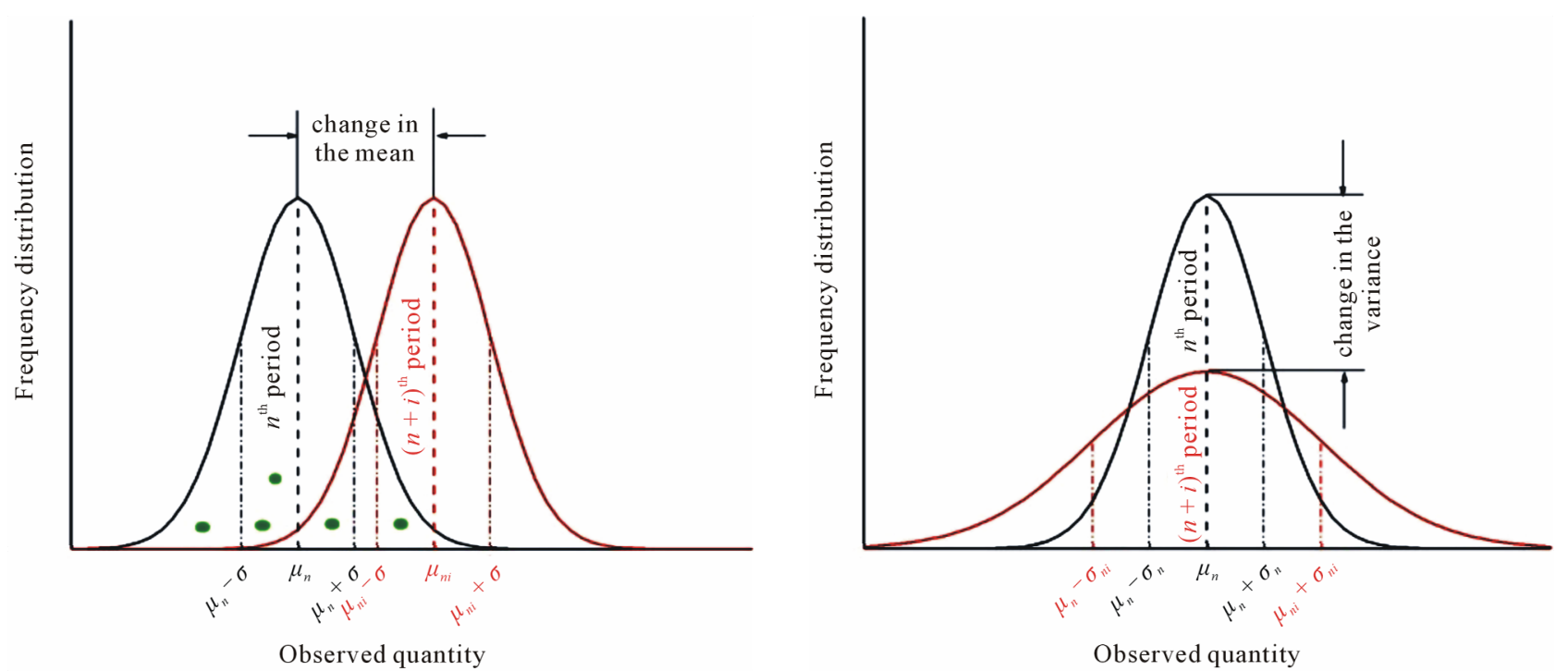

Observed quantity

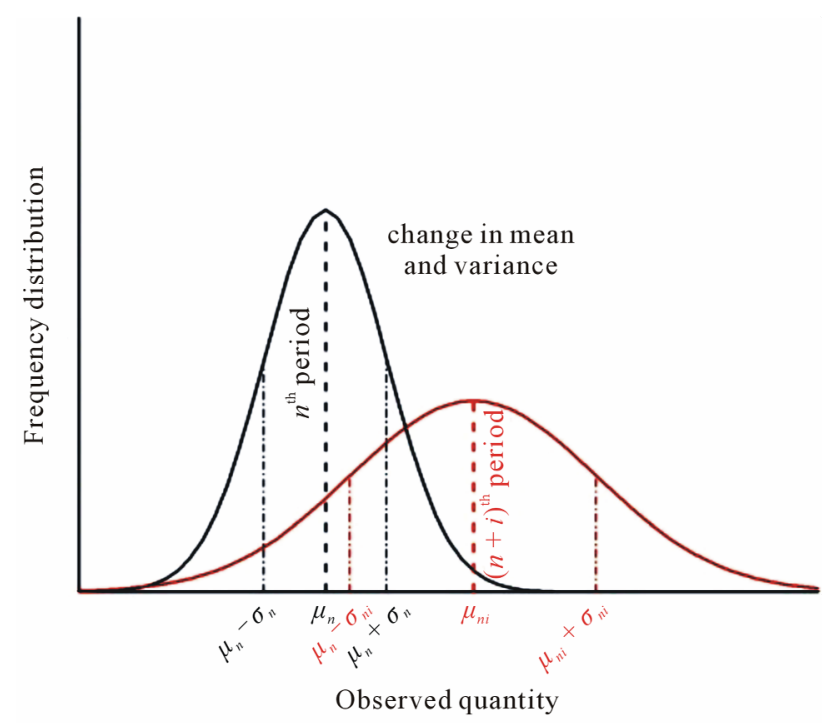

Figure 13. For distinction between weather and climate (adopted from Meehl et al. [107] and Schönwiese [11]). The black curve always characterize the climate of a location or region for the $n^{\text {th }}$ climate period (usually 30 years) at the hand of a frequency distribution of an observed quantity of the corresponding weather events (simply illustrated some green dots) assumed to be a normally distributed random variable. This probability density function (PDF) of this climate period is characterized by the mean value, $\mu_{n}$ and the standard deviation, $\sigma_{n}$. The red curves characterize the $(n+i)^{\text {th }}$ climate period, $i= \pm 1, \pm 2$, $\cdots$, where for the purpose of simplification a similar PDF is assumed. In case of a change from the $n^{\text {th }}$ climate period to the $(n+i)^{\text {th }}$ climate, the mean values, $\mu_{n}$ and $\mu_{n i}$ and/or the standard deviations, $\sigma_{n}$ and $\sigma_{n i}$, can differ from each other indicating, for instance, a change in the occurrence of extreme weather events.

because describing the weather states in a statistical manner requires that the weather states of a climate period can be characterized by a strong degree of randomness. This means that the scope of the statistical climatology clearly differs from that of the physical climatology, but the mean values might be related to the boundary conditions of the climate system under study. Such a distinction between statistical and physical descriptions of a system is well known in turbulence research.

As pointed out by Monin and Shishkov [10] and
Schönwiese [11], the thirty-year period for defining the characteristics of the current climate of the atmosphere is based on the recommendation of the international meteorological conferences of 1935 inWarsaw and of 1957 in Washington. Typical climate periods are 1901-1930, 1931-1960 and 1961-1990. They are called the climate normals (CLINOs). Currently, the CLINO 1971-2000 is considered in the United States of America (http:/www. ncdc.noaa.gov/oa/climate/normals/usnormalsprods.html). Since any change can only be identified with respect to a 
reference state (e.g., a CLINO), climate change can only be diagnosed on the basis of two non-overlapping climate periods for which, at least, 60 year-observation records are required. Figure 14 shows trends of the annual temperature anomaly for the Northern Hemisphere and the annual carbon dioxide concentration at Mauna Loa, Hawaii with respect to the Climate Normal 19611990. Such trends are often considered as an indication for climate change. From a statistical point of view, such trends are rather inappropriate for describing climate change and climate variability, respectively.

The notion "climate change", in principle, means that the climate of a location or region has so drastically been changed that it has switched from one climate zone to another. This, however, is seldom the case. Instead, the climate of a location or region varies from one nonoverlapping climate period to another without leaving its climate zone. It can be described the best by the notion "climate variability".

Since it is rather difficult or probably impossible to identify in which way the atmospheric greenhouse effect is acting on weather states, we must not expect that the statistical description of weather states for various climate periods can provide any reasonable result. Thus, only the branch of physical climatology, if at all, might be helpful in this matter.

\section{THE EXPLANATION OF THE GREENHOUSE EFFECT BY THE AMERICAN METEOROLOGICAL SOCIETY}

In the Glossary of Meteorology of the AMS, the atmospheric greenhouse effect is explained by (http:// amsglossary.allenpress.com/glossary/search?id=greenhouse-effect 1):

"The heating effect exerted by the atmosphere upon the Earth because certain trace gases in the atmosphere (water vapor, carbon dioxide, etc.) absorb and reemit infrared radiation.

Most of the sunlight incident on the Earth is transmitted through the atmosphere and absorbed at the Earth's surface. The surface tries to maintain energy balance in part by emitting its own radiation, which is primarily at the infrared wavelengths characteristic of the Earth's temperature. Most of the heat radiated by the surface is absorbed by trace gases in the overlying atmosphere and reemitted in all directions. The component that is radiated downward warms the Earth's surface more than would occur if only the direct sunlight were absorbed. The magnitude of this enhanced warming is the greenhouse effect. Earth's annual mean surface temperature of $15^{\circ} \mathrm{C}$ is $33^{\circ} \mathrm{C}$ higher as a result of the greenhouse effect than the mean temperature resulting from radiative

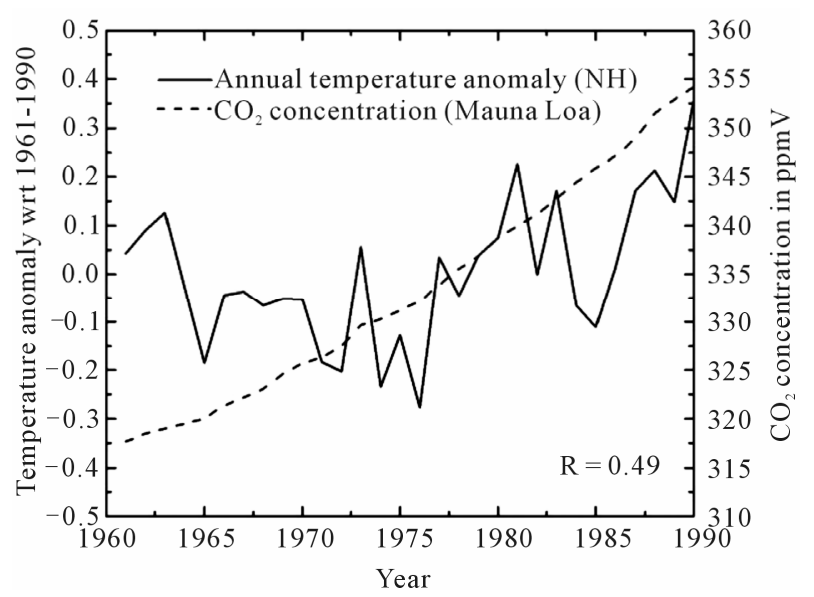

Figure 14. Trends of the annual temperature anomaly for the Northern Hemisphere (NH, source: Hadley Centre for Climate Prediction and Research, MetOffice, UK) and the annual carbon dioxide concentration at Mauna Loa, Hawaii (source: Mauna Loa Observatory, National Oceanic and Atmospheric Administration, NOAA), with respect to the Climate Normal 1961-1990. The quantity $\mathrm{R}$ is the correlation coefficient.

equilibrium of a blackbody at the Earth's mean distance from the Sun. The term "greenhouse effect" is something of a misnomer. It is an analogy to the trapping of heat by the glass panes of a greenhouse, which let sunlight in. In the atmosphere, however, heat is trapped radiatively, while in an actual greenhouse, heat is mechanically prevented from escaping (via convection) by the glass enclosure."

The explanation of the WMO that can be found, for instance, in its contribution entitled Understanding Climate (http://www.W·mo.int/pages/themes/climate/understanding climate.php) reads:

"In the atmosphere, not all radiation emitted by the Earth surface reaches the outer space. Part of it is reflected back to the Earth surface by the atmosphere (greenhouse effect) leading to a global average temperature of about $14^{\circ} \mathrm{C}$ well above $-19^{\circ} \mathrm{C}$ which would have been felt without this effect."

Even though some numbers slightly differ from each other $\left(15^{\circ} \mathrm{C}\right.$ by $\mathrm{AMS} ; 14^{\circ} \mathrm{C}$ by WMO $)$ in both explanations the temperature difference of $33^{\circ} \mathrm{C}$ serves to quantify the atmospheric greenhouse effect. Note that the argument that "part of it is reflected back to the Earth surface by the atmosphere" is completely irrational from a physical point of view. Such an argument also indicates that the discipline of climatology has lost its rational basis. Thus, the explanation of the WMO is rejected.

With respect to the explanation of the AMS we may carry out the following "thought experiment" of a planetary radiative equilibrium, where we assume the Earth in the absence ofan atmosphere. A consequence of 
this assumption is that atmospheric phenomena like 1) absorption of solar and terrestrial (infrared) radiation, 2) scattering of solar radiation by molecules and particulate matter, 3) emission of energy in the infrared range, 4) convection and advection of heat and 5) phase transition processes related to the formation and depletion of clouds play no role [21]. The incoming flux of solar radiation, $F_{S \downarrow}$, that is absorbed at the Earth's surface is, therefore, given by [70]

$$
F_{S \downarrow}=\pi r_{E}^{2}\left(1-\alpha_{E}\right) S
$$

Here, $r_{E} \cong 6371 \mathrm{~km}$ is the mean radius of the Earth considered as a sphere, and $\alpha_{E}$ is the planetary albedo of the Earth (see also Table 2); the value of $\alpha_{E}=0.30$ is based on satellite observations of the system Earthatmosphere [26] and significantly differs from the mean albedo of the Earth's surface.

If we assume that the temperature, $T_{e}$, of the Earth's surface is uniformly distributed, i.e., it is assumed that it depends neither on the longitude nor on the latitude, the total flux of infrared radiation emitted by the Earth's surface, $F_{I R \uparrow}$, as a function of this temperature and the planetary emissivity, $\varepsilon_{E} \leq 1$, will be given by [70].

$$
F_{I R \uparrow}=4 \pi r_{E}^{2} \varepsilon_{E} \sigma T_{e}^{4}
$$

This equation is based on the power law of Stefan [66] and Boltzmann [67]. If we further assume that there is a so-called planetary radiative equilibrium, i.e., $F_{S \downarrow}=F_{I R \uparrow}$, we will obtain (e.g., [15,26,27,70-72]).

$$
S\left(1-\alpha_{E}\right)=4 \varepsilon_{E} \sigma T_{e}^{4}
$$

This equation characterizes the planetary radiation balance of this simplified system. Rearranging this equation yields

$$
T_{e}=\left(\frac{\left(1-\alpha_{E}\right) S}{4 \varepsilon_{E} \sigma}\right)^{\frac{1}{4}} .
$$

Assuming that the Earth is acting like a black body $\left(\varepsilon_{E}=1\right.$ ) and using $S \cong 1367 \mathrm{~W} \cdot \mathrm{m}^{-2}$ and $\alpha_{E}=0.30$ lead to $T_{e}=254.9 \mathrm{~K}$ (or $T_{e}=254.6 \mathrm{~K}$ for $S \cong 1361 \mathrm{~W} \cdot \mathrm{m}^{-2}$ ). Since in case of the real Earth-atmosphere system the global average of air temperatures observed in the close vicinity of the Earth's surface corresponds to $\left\langle T_{n s}\right\rangle=$ $288 \mathrm{~K}$, the difference between this mean global temperature and the temperature of the planetary radiative equilibriumgiven by Eq.3.4 amounts to $\Delta T=\left\langle T_{n s}\right\rangle-T_{e} \approx$ $33 \mathrm{~K}$. Therefore, as stated in the Glossary Of Meteorology of the AMS, the so-called greenhouse effect of the atmosphere causes a temperature increase of about $33 \mathrm{~K}$, regardless of the fact that the atmosphere is an thermodynamically open system in which various atmospheric processes listed before may take place, but not a simple greenhouse that causes the trapping of solar radiation [21].

Möller [70] — to our best knowledge — introduced Eqs. 3.1 to 3.4 into the literature without any scientific justification of the assumptions on which these equations are based. Thus, it is indispensable to assess these assumptions and the result of $T_{e}=254.9 \mathrm{~K}$ which is based on them:

1) Only a planetary radiation budget of the Earth in the absence of an atmosphere is considered, i.e., any heat storage in the oceans (if at all existing in such a case) and land masses is neglected.

2) The assumption of a uniform surface temperature for the entire globe is rather inadequate. As shown by Kramm and Dlugi [21] this assumption is required by the application of the power law of Stefan [66] and Boltzmann [67] because, as mentioned before, this power law is determined a) by integrating Planck's [29] blackbody radiation law, for instance, over all wavelengths ranging from zero to infinity and b) by integrating the isotropic emission of radiant energy by a small spot of the surface into the adjacent half space (e.g., $[15,68])$. Thus, applying the Stefan-Boltzmann power law to a statistical quantity like $\left\langle T_{n s}\right\rangle$ cannot be justified by physical and mathematical reasons. Even in the real situation of an Earth enveloped by its atmosphere there is a notable variation of the Earth's (near-) surface temperature from the equator to the poles owing to the varying solar insolation at the TOA (see Figure 6) and from daytime to nighttime. Consequently, the assumption of a uniform surface temperature cannot be justified. Our Moon, for instance, nearly satisfies the requirements of a planet in the absence of an atmosphere. It is well known that the Moon has no uniform surface temperature. There is not only a strong variation of its surface temperature from the lunar day to the lunar night, but also from its equator to its poles (e.g., [73-75]). In addition, ignoring the heat storage would lead to a surface temperature of the Moon during lunar night of $0 \mathrm{~K}$ (or $2.7 \mathrm{~K}$, the temperature of the space, see also Formula 3.11).

3) The choice of the planetary albedo of $\alpha_{E}=0.30$ is rather inadequate. This value is based on satellite observations and, hence, contains not only the albedo of the Earth's surface, but also the back scattering of solar radiation by molecules (Rayleigh scattering), cloud and aerosol particles (Lorenz-Mie scattering). Budyko [76] already stated that in the absence of an atmosphere the planetary albedo cannot be equal to the actual value of $\alpha_{E}=0.33$ (at that time, but today $\alpha_{E}=0.30$ ). He assumed that prior to the origin of the atmosphere, the Earth's albedo was lower and probably differed very little from the Moon's albedo, which is equal to $\alpha_{M}=$ 
0.07 (at that time, but today $\alpha_{M}=0.12$ ). A planetary surface albedo of the Earth of about $\alpha_{E}=0.07$ is also suggested by the results of Trenberth et al. [44] (see Figure 15). Thus, if a planetary surface albedo of $\alpha_{E}=$ 0.07 and a planetary emissivity of $\varepsilon_{M}=1$ (black body) are considered, Eq.3.4 will provide: $T_{e}=273.6 \mathrm{~K}$. For $\alpha_{E}=0.12$ one obtains: $T_{e}=269.9 \mathrm{~K}$. Note that Haltiner and Martin [24] argued that the mean surface temperature of the Moon must satisfy the condition of radiative equilibrium so that $T_{e}=266 \mathrm{~K}$ (the authors used $S=$ $1.94 l y \mathrm{~min}^{-1}, \sigma=8.17 \times 10^{-11} l y \mathrm{~min}^{-1} \mathrm{~K}^{-4}$ and $\alpha_{M}=0.10$, but this result is slightly too low), as contrasted with the Earth's temperature of $\left\langle T_{n s}\right\rangle=288 \mathrm{~K}$. Obviously, they tried to explain the so-called atmospheric greenhouse effect by the difference between the Moon's surface temperature at radiative equilibrium and the globally averaged near-surface temperature of the Earth.

4) Comparing $T_{e}$ with $\left\langle T_{n s}\right\rangle$ is rather inappropriate because the meaning of these temperatures is quite different. The former is based on an energy-flux budget at the surface even though it is physically inconsistent because a uniform temperature for the entire globe does not exist. Whereas the latter is related to globally averaging of near-surface temperature observations carried out at the stations of the meteorological network (supported by satellite observations), where the global average is defined by $[2,21,77]$

$$
\langle\Phi\rangle=\frac{r_{E}^{2} \int_{\Omega} \Phi(\theta, \varphi) \mathrm{d} \Omega}{r_{E}^{2} \int_{\Omega} \mathrm{d} \Omega}=\frac{1}{4 \pi} \int_{\Omega} \Phi(\theta, \varphi) \sin \theta \mathrm{d} \theta \mathrm{d} \varphi .
$$

Here, $\Phi(\theta, \varphi)$ is an arbitrary quantity (e.g., surface temperature, precipitation), $\Omega=4 \pi$ is the solid angle of a sphere and $d \Omega=\sin \theta \mathrm{d} \theta \mathrm{d} \varphi$ is the differential solid angle, where, again, $\theta$ and $\varphi$ are the zenith and azimuthal angles, respectively.

5) As illustrated in Figure 16, the Moon's mean disk temperature observed at $2.77 \mathrm{~cm}$ wavelength by Monstein [78] is much lower than $T_{e}=269.9 \mathrm{~K}$ which can be derived with the Moon's planetary albedo of $\alpha_{M}=$ 0.12. Even though the Moon's mean disk temperature observed in 1948 by Piddington and Minnett [79] is of about $26 \mathrm{~K}$ higher than that of Monstein [78], it is still

Global Energy Flows W· m ${ }^{2}$

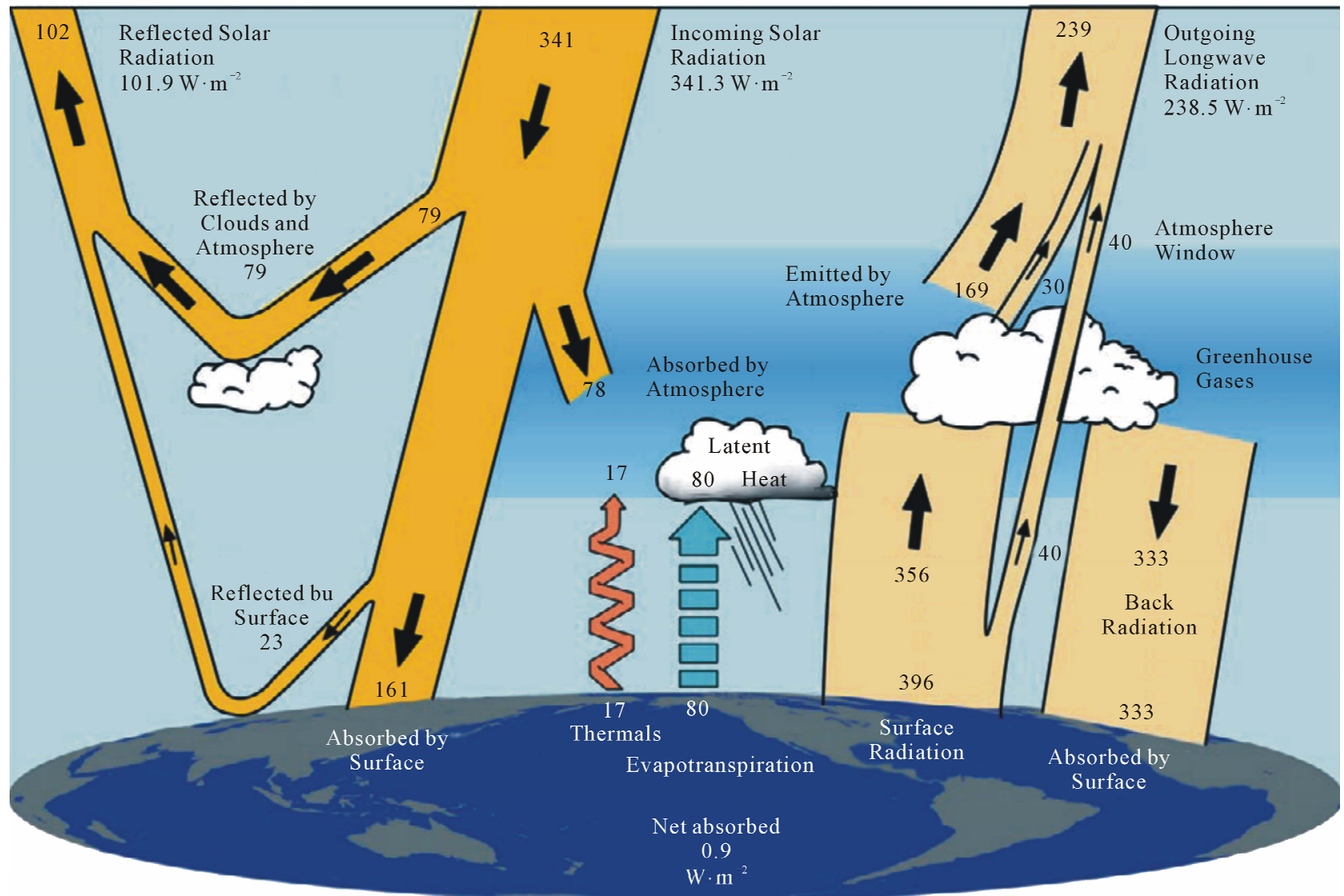

Figure 15. The global annual mean Earth's energy budget for the Mar 2000 to May 2004 period $\left(\mathrm{W} \cdot \mathrm{m}^{-2}\right)$. The broad arrows indicate the schematic flow of energy in proportion to their importance (adopted from Trenberth et al. [44]). 


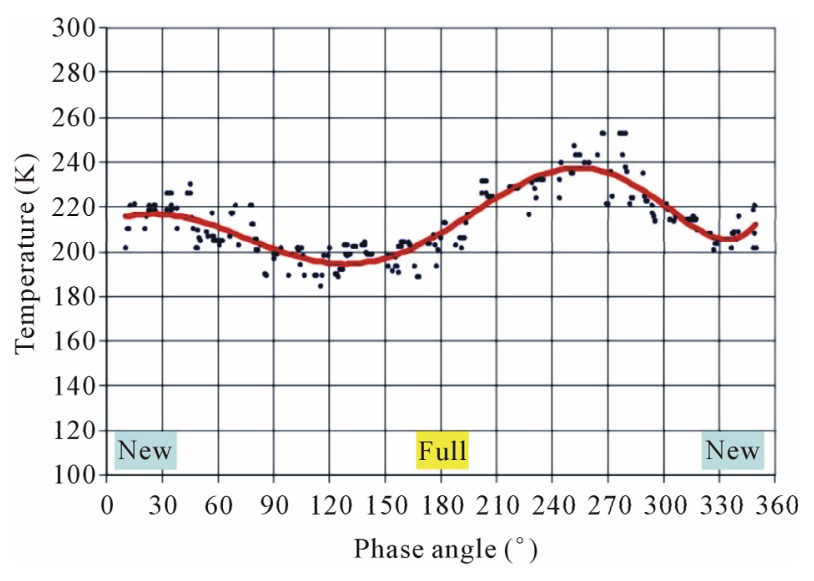

Figure 16. Moon's disk temperature at $2.77 \mathrm{~cm}$ wavelength versus moon phase angle $\varphi$ during two complete cycles from twice new moon via full moon to new moon again (adopted from Monstein [78]).

$31 \mathrm{~K}$ lower than $T_{e}=269.9 \mathrm{~K}$. Since the Moon is nearly a perfect example of a planet in the absence of its atmosphere it is often argued that Eqs.3.3 and 3.4 are only valid for fast-rotating planets so that the Moon must be excluded. Obviously, this argument plays no role if the planet Venus is considered that rotates by a factor of four slower than the Moon. Recently, Pierrehumbert [80] used Eq.3.4 to calculate the temperature of the planetary radiative equilibrium. With $\alpha_{V}=0.75$ and $\varepsilon_{V}=1$ he obtained $T_{e}=231 \mathrm{~K}$. If we chose $\alpha_{V}=0.12$ for the Venus in the absence of its atmosphere (which is similar to that of the Moon) we will obtain $T_{e}=317.3 \mathrm{~K}$ and for $\alpha_{V}=0.90$ as listed in NASA's Venus Fact Sheet (http://nssdc.gsfc.nasa.gov/planetary/factsheet/venusfact. html) $T_{e}=184.2 \mathrm{~K}$.

Because of these facts we may conclude that Eq.3.4 is based on assumptions that are physically irrelevant and the results obtained with it considerably disagree with observations. Consequently, the difference of $\Delta T=\left\langle T_{n s}\right\rangle-T_{e} \approx 33 \mathrm{~K}$ cannot be justified by physical reasons.

Even though Gerlich and Tscheuschner [2] already criticized it because of its physical irrelevance, Lacis et al. [81] completely ignore it when they stated recently:

"The difference between the nominal global mean surface temperature $\left(T_{S}=288 \mathrm{~K}\right)$ and the global mean effective temperature $\left(T_{E}=255 \mathrm{~K}\right)$ is a common measure of the terrestrial greenhouse effect $\left(G_{T}=T_{S}-T_{E}=33 \mathrm{~K}\right)$. Assuming global energy balance, $T_{E}$ is also the Planck radiation equivalent of the $240 \mathrm{~W} / \mathrm{m}^{2}$ of global mean solar radiation absorbed by Earth."

Note that their temperature $T_{S}$ corresponds to our $\left\langle T_{n s}\right\rangle$ and $T_{E}$ to our $T_{e}$. Calling the globally averaged irradiance of $240 \mathrm{~W} \cdot \mathrm{m}^{-2}$ the "Planck radiation equivalent" shows that the authors are less familiar with basic physics in this matter. Planck's [29] blackbody radiation law describes the monochromatic intensity (also called the monochromatic radiance), usually expressed by $\mathrm{W} \cdot \mathrm{m}^{-2}$ $\mu \mathrm{m}^{-1} \cdot \mathrm{sr}^{-1}$, as a function of temperature $[15,68]$. As mentioned before, the power law of Stefan [66] and Boltzmann [67] has to be applied to calculate the irradiance usually expressed by $\mathrm{W} \cdot \mathrm{m}^{-2}$. This power law was already used by Wien [82] as a constraint in deriving his blackbody radiation law which is an asymptotic solution of Planck's radiation law mainly for shorter wavelengths. This power law is also a constraint for Planck's radiation law.

Even in case of this thought experiment we have to consider that the temperature $T(\theta, \varphi)$ has to be determined on the basis of an energy-flux budget (instead of a radiation-flux budget) at a certain location given, at least, by (the diffuse solar radiation, the down-welling IR radiation and the fluxes of sensible and latent heat that occurred in Eq.2.17 can be ignored)

$$
\begin{aligned}
& \left(1-\alpha_{S}\left(\Theta_{0}, \theta, \varphi\right)\right) F \cos \Theta_{0}-\varepsilon(\theta, \varphi) \sigma T_{s}^{4}(\theta, \varphi) \\
& +G(\theta, \varphi)=0
\end{aligned}
$$

leading to

$$
T_{s}(\theta, \varphi)=\left\{\frac{G(\theta, \varphi)+\left(1-\alpha_{S}\left(\Theta_{0}, \theta, \varphi\right)\right) F \cos \left(\Theta_{0}\right)}{\varepsilon(\theta, \varphi) \sigma}\right\}^{\frac{1}{4}}
$$

Here, $F$ is the solar irradiance reaching a surface element of the globe. All other symbols have the same meaning as given before (see Eq.2.17).

Inserting Formula 3.7 into Eq.3.5 yields

$$
\begin{aligned}
\left\langle T_{s}\right\rangle= & \frac{1}{4 \pi} \int_{0}^{2 \pi} \int_{0}^{\pi}\left\{\frac{\left(1-\alpha_{S}\left(\Theta_{0}, \theta, \varphi\right)\right) F \cos \left(\Theta_{0}\right)}{\varepsilon(\theta, \varphi) \sigma}\right. \\
& \left.+\frac{G(\theta, \varphi)}{\varepsilon(\theta, \varphi) \sigma}\right\}^{\frac{1}{4}} \sin \theta \mathrm{d} \theta \mathrm{d} \varphi
\end{aligned}
$$

This integration can only be performed numerically because $\Theta_{0}$ depends on time (see Eq.2.9). Using Eq. 3.8 and ignoring $G(\theta, \varphi)$ will lead to

$$
\left\langle T_{s}\right\rangle=\frac{2^{\frac{3}{2}}}{5} T_{e} \approx 144 \mathrm{~K}
$$

for a non-rotating Earth in the absence of its atmosphere, if $S \cong 1367 \mathrm{~W} \cdot \mathrm{m}^{-2}, \alpha_{S}\left(\Theta_{0}, \theta, \varphi\right)=\alpha_{E}=0.30$ and $\varepsilon(\theta, \varphi)=\varepsilon_{E}=1$ are assumed [2] $\left(\left\langle T_{s}\right\rangle \approx 153 \mathrm{~K}\right.$ if $\alpha_{E}=$ 0.12 and $\left\langle T_{s}\right\rangle \approx 155 \mathrm{~K}$ if $\left.\alpha_{E}=0.07\right)$. It seems, however, that this globally averaged surface temperature for the Earth in the absence of its atmosphere is as unrealistic as the temperature of the radiative equilibrium of 
$T_{e}=254.9 \mathrm{~K}$. Consequently, as already argued by Gerlich and Tscheuschner [2] it is indispensable to determine the true globally averaged surface temperature for the obliquely rotating Earth by using Eq.3.8. This means that also the ground heat flux, $G(\theta, \varphi)$, has to be included. The direction of $G(\theta, \varphi)$ is mainly governed by the difference between the absorbed incoming solar radiation and the emission of infrared radiation. For the dark side of a planet having no atmosphere the energyflux balance Eq.3.6 reduces to

$$
\varepsilon(\theta, \varphi) \sigma T_{s}^{4}(\theta, \varphi)=G(\theta, \varphi)
$$

This energy-flux balance provides

$$
T_{s}(\theta, \varphi)=\left\{\frac{G(\theta, \varphi)}{\varepsilon(\theta, \varphi) \sigma}\right\}^{\frac{1}{4}}
$$

If we assume, for instance, a surface temperature of $T_{s}(\theta, \varphi)=130 \mathrm{~K}$ on the dark side of the Moon and choose $\varepsilon(\theta, \varphi)=1$, the ground heat flux will amount to $G(\theta, \varphi) \cong 16.2 \mathrm{~W} \cdot \mathrm{m}^{-2}$. Without the ground heat flux the predicted surface temperature (see Formula 3.11), for instance, on the dark side of the Moon would be equal to zero (or to the temperature of the space of about $2.7 \mathrm{~K}$ as mentioned before). Consequently, the ground heat flux is not generally negligible.

\section{THE EXPLANATION OF THE GREENHOUSE EFFECT BY RAMANATHAN ET AL.}

In their review paper Ramanathan et al. [1] stated:

\section{REFERENCE ATMOSPHERE}

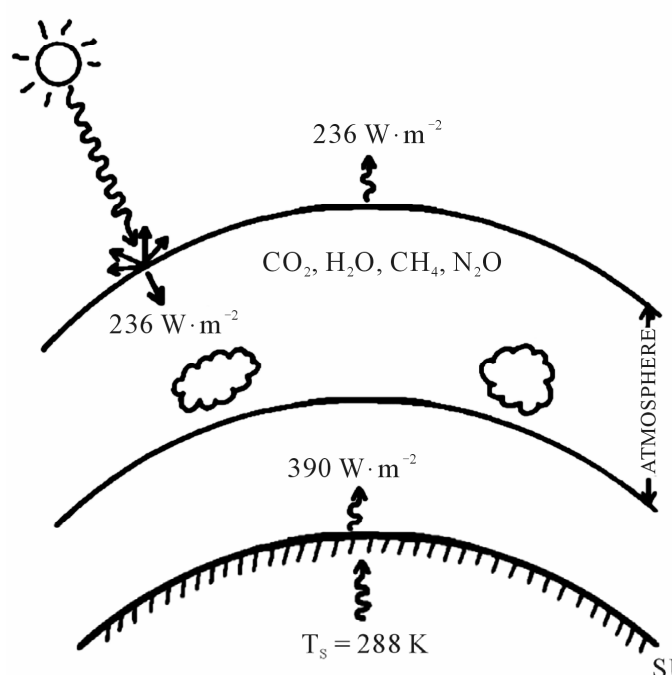

"The incoming solar radiation, the reflected solar radiation and the outgoing long-wave radiation at the top of the atmosphere have been determined by satellite radiation budget measurements and the values inferred from these measurements are shown in Figure 2 [here presented as Figure 17]. The surface-atmosphere system emits to space roughly $236 \mathrm{~W} \cdot \mathrm{m}^{-2}$, which balances the absorbed solar radiation. The emitted radiation is mostly contained in wavelengths longer than $4 \mu \mathrm{m}$ and hence it is referred to as long-wave, infrared (IR), or terrestrial radiation.

At a surface temperature of $288 \mathrm{~K}$ the long-wave emission by the surface is about $390 \mathrm{~W} \cdot \mathrm{m}^{-2}$, whereas the outgoing long-wave radiation at the top of the atmosphere is only $236 \mathrm{~W} \cdot \mathrm{m}^{-2}$ (see Figure 2 [here presented as Figure 17]). Thus the intervening atmosphere causes a significant reduction in the long-wave emission to space. This reduction in the long-wave emission to space is referred to as the greenhouse effect."

Haltiner and Martin [24] already argued in a similar manner. As discussed before, applying the power law of Stefan and Boltzmann to a globally averaged temperature cannot be justified by physical and mathematical reasons. Thus, the argument that at a surface temperature of $288 \mathrm{~K}$ the long-wave emission by the surface is about $390 \mathrm{~W} \cdot \mathrm{m}^{-2}$ is meaningless.

Figure 5 illustrates that the wavelength of about $4 \mu \mathrm{m}$ mentioned before separates the band comprising most of the solar radiation (black line) from that comprising most of the terrestrial (infrared) radiation (red line). This seems to be awkward because, according to Wien's [83] displacement law, the spectral radiation intensities for

\section{WITH CFC's}
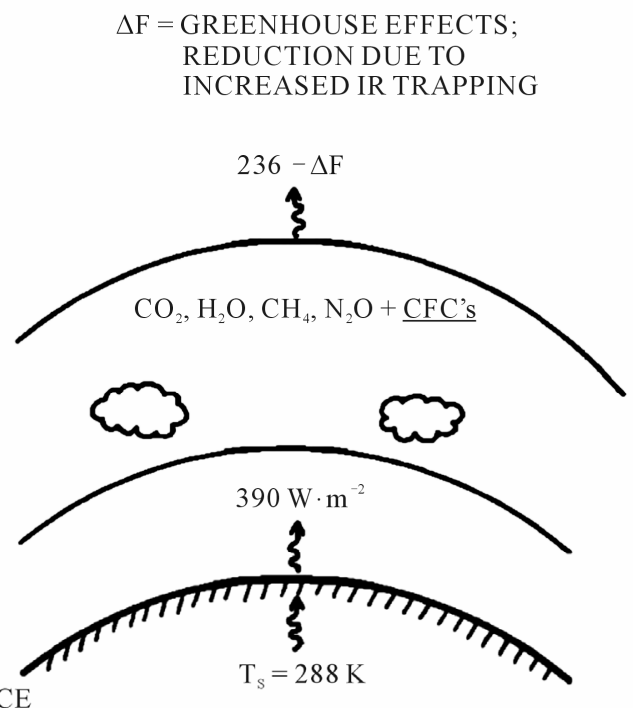

Figure 17. Global energy balance and the greenhouse effect (adopted from Ramanathan et al., [1]). 
different temperatures must not intersect each other. To understand the intersection at a wavelength of about 4 $\mu \mathrm{m}$, we have, therefore, to consider the solar irradiance reaching the TOA as expressed by Eq.2.12.

Recently, Trenberth et al. [44] published an update of the Earth's global energy-flux budget. Their results are illustrated in Figure 15. These results slightly differ from those previously published by various authors (see Table 2), but these slight differences are much larger than the globally averaged net anthropogenic radiative forcing that corresponds to $R F=1.6(0.6$ to 2.4$) \mathrm{W} \cdot \mathrm{m}^{-2}$ in 2005 relative to pre-industrial conditions defined at 1750 (see Figure 18).

According to Dines [84], Trenberth et al. [44] and others the global energy budget for the system Earthatmosphere may be written as:

Top of the atmosphere:

$$
\left(1-\alpha_{E}\right) \frac{S}{4}-R_{O L}=0
$$

Earth's surface:

$$
\left(1-\alpha_{E}-A_{a}\right) \frac{S}{4}-\Delta R_{L \uparrow}-H-E-I=0
$$

Here, $A_{a}=0.23$ is the absorptivity of the atmosphere with respect to solar radiation (see Table 2). Furthermore, $R_{O L}$ is the outgoing infrared radiation at the TOA. According to Trenberth et al. [44] this value is

Radiative Forcing Components

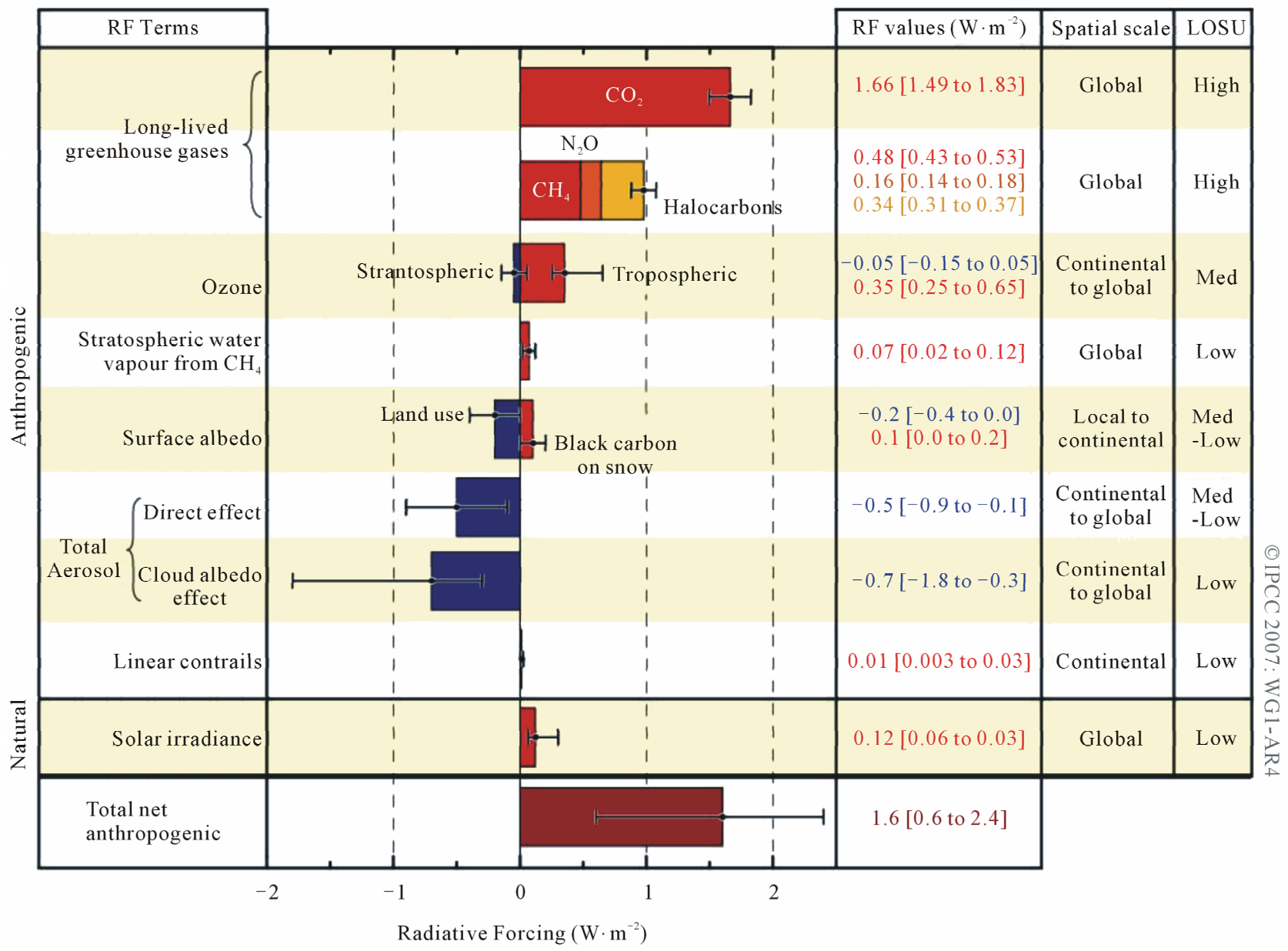

Figure 18. Global-average radiative forcing (RF) estimates and ranges in 2005 for anthropogenic carbon dioxide $\left(\mathrm{CO}_{2}\right)$, methane $\left(\mathrm{CH}_{4}\right)$, nitrous oxide $\left(\mathrm{N}_{2} \mathrm{O}\right)$ and other important agents and mechanisms, together with the typical geographical extent (spatial scale) of the forcing and the assessed level of scientific understanding (LOSU). The net anthropogenic radiative forcing and its range are also shown. These require summing asymmetric uncertainty estimates from the component terms and cannot be obtained by simple addition. Additional forcing factors not included here are considered to have a very low LOSU. Volcanic aerosols contribute an additional natural forcing but are not included in this figure due to their episodic nature. Range for linear contrails does not include other possible effects of aviation on cloudiness (adopted from the Intergovernmental Panel on Climate Change, Climate Change 2007Summary for Policymakers, with respect to Forster et al. [108]). 
balancing the difference between the incoming solar radiation minus the solar radiation back scattered by the entire Earth-atmosphere system (see Eq.4.1). Moreover, $\mathrm{H}=17 \mathrm{~W} \cdot \mathrm{m}^{-2}$ and $E=80 \mathrm{~W} \cdot \mathrm{m}^{-2}$ are the fluxes of sensible and latent heat, respectively; and $\Delta R_{L \uparrow}=63 \mathrm{~W} \cdot \mathrm{m}^{-2}$ is the so-called net infrared radiation $[32,85]$ (see also Table 2). The term $I=0.9 \mathrm{~W} \cdot \mathrm{m}^{-2}$ is a remainder to close the energy-flux balance. Trenberth et al. [44] interpreted this term as a net downward radiation. This is clearly a misinterpretation because it has to be linked to the storage of energy (eventually in form of coal and petroleum [31]), the heat transfer by precipitation and/or non-stationary effects. Thus, Eq.4.2 mainly describes the partitioning of the absorbed solar radiation into the flux terms $H, E$ and $\Delta R_{L \uparrow}$ that serve to heat the atmosphere via the Earth's surface. The results of various authors listed in Table 2 reflect this kind of energy partitioning regardless the wide variety of $\Delta R_{L \uparrow}$ values ranging from $46 \mathrm{~W} \cdot \mathrm{m}^{-2}$ to $72 \mathrm{~W} \cdot \mathrm{m}^{-2}$.

Combining Eqs.4.1 and 4.2 yields (hereafter the remainder $I$ is omitted)

$$
\left(1-\alpha_{E}\right) \frac{S}{4}=R_{O L}=A_{a} \frac{S}{4}+\Delta R_{L \uparrow}+H+E .
$$

This means that the solar irradiance at the TOA reduced by the amount reflected by the atmosphere (back scattering by molecules, cloud and aerosol particles) and the Earth's surface is heating the system Earth-atmosphere, namely 1) directly by absorption in the atmosphere $\left(A_{a} S / 4\right)$ and 2$)$ indirectly via the energy conversion at the Earth's surface ( $H$ and $\Delta R_{L \uparrow}$ ), where the flux term $E$ is linked to the reservoir of latent energy (see Figure 11). As illustrated in Figure 11, $A_{a} S / 4, H$ and $\Delta R_{L \uparrow}$ contributes to the reservoir of total potential energy $(\mathrm{TPE}=$ internal plus potential energy). The reservoir of latent energy mainly maintains atmospheric circulations and cycles, where the accompanied condensation of water vapor forms clouds and, hence, contributes to the reservoir of the TPE that also supports the maintenance of atmospheric circulations and cycles. Only a very small amount of the TPE is available for converting into kinetic energy [31,86-89]. As expressed by Eq.4.3 and illustrated by Figure 11, the outgoing infrared radiation at the TOA, $R_{O L}$, balances the energy input into the reservoir of total potential energy. Thus, the "cycle" of the long-wave radiation between that Earth's surface and the atmosphere does not contribute to the heating of the system as already pointed out by Fortak [31]. We share Fortak's [31] argument that the outgoing emission of infrared radiation only serves to maintain the radiative equilibrium at the TOA (see Eq.4.1).

Let us further discuss the term $\Delta R_{L \uparrow}$. According to Haltiner and Martin [24], Möller [85], Ramanathan et al.
[1] and Trenberth et al. [44] and many others this term is given by

$$
\Delta R_{L \uparrow}=\varepsilon_{E} \sigma\left\langle T_{s}\right\rangle^{4}-\varepsilon_{E} R_{L \downarrow}=\varepsilon_{E}\left(\sigma\left\langle T_{s}\right\rangle^{4}-R_{L \downarrow}\right)
$$

where $\left\langle T_{s}\right\rangle$ is the globally averaged Earth's surface temperature and $R_{L \downarrow}$ is the down-welling infrared radiation. As discussed in Subsection 2.1.2, the latter is mainly caused by the temperature distribution in the troposphere linked to convective heating and the release of latent heat and the temperature distribution in the stratosphere related to the absorption of solar radiation by $\mathrm{O}_{2}$ and $\mathrm{O}_{3}$ molecules, respectively. Despite the fact that the global emission of infrared radiation by the Earth's surface cannot be determined using a globally averaged (near-)surface temperature, $\left\langle T_{n s}\right\rangle=288 \mathrm{~K}$ would lead to an emission of $390 \mathrm{~W} \cdot \mathrm{m}^{-2}$ if $\varepsilon_{E}=1$ is assumed (e.g., [1]). Using a more realistic value of $\varepsilon_{E}=0.95$, however, would provide $371 \mathrm{~W} \cdot \mathrm{m}^{-2}$. These two results simply document that an attempt to diagnose a remainder of $I=0.9 \mathrm{~W} \cdot \mathrm{m}^{-2}$ so accurately is far beyond our means with which geophysical processes can be analyzed. They also document that $R_{L \downarrow}=\varepsilon_{E} \sigma\left\langle T_{n s}\right\rangle^{4}-\Delta R_{L \uparrow}$ would be varying by $19 \mathrm{~W} \cdot \mathrm{m}^{-2}$ if $\varepsilon_{E}$ is ranging from $\varepsilon_{E}=0.95$ to $\varepsilon_{E}=1$.

In two-layer radiative equilibrium models involving the Earth's surface and the atmosphere with homogeneous temperatures $T_{E}$ and $T_{a}$, respectively, the downwelling infrared radiation is parameterized by $R_{L \downarrow}=$ $\varepsilon_{a} \sigma T_{a}^{4}$ [15]. If we assume, for instance, $\varepsilon_{E}=1$ and an integral emissivity of the atmosphere of $\varepsilon_{a}=0.75$, a homogeneous Earth's surface temperature of $T_{E}=288 \mathrm{~K}$ and a homogeneous radiative temperature of the atmosphere of $T_{a}=296.1 \mathrm{~K}$, we will also obtain: $\Delta R_{L \uparrow}=63$ $\mathrm{W} \cdot \mathrm{m}^{-2}$. The same is true for the following pairs of temperatures $T_{E}=273 \mathrm{~K}$ and $T_{a}=277.4 \mathrm{~K}$ as well as $T_{E}=$ $255 \mathrm{~K}$ and $T_{a}=253.9 \mathrm{~K}$. Since $\Delta R_{L \uparrow}$ is only one of the flux terms related the partitioning of absorbed solar radiation the temperature $\left\langle T_{n s}\right\rangle=288 \mathrm{~K}$ cannot be introduced into Eq.4.2 (as done by Haltiner and Martin [24] and Ramanathan et al. [1]) because the globally averaged Earth's surface temperature is statistically determined on the basis of (near-)surface observations. It has no physical link to the global energy-flux budget scheme in which representative temperatures for the Earth's skin and the entire atmosphere occur. This fact can be explained at the hand of a Dines-type scheme for the global energy balance of the Earth-atmosphere system [84] expressed by the following pair of equations [21,77]:

Top of the atmosphere:

$$
\left(1-\alpha_{E}\right) \frac{S}{4}-\varepsilon_{a} \sigma T_{a}^{4}-\left(1-\varepsilon_{a}\right) \varepsilon_{E} \sigma T_{E}^{4}=0
$$

Earth's surface: 


$$
\left(1-\alpha_{E}-A_{a}\right) \frac{S}{4}+\varepsilon_{E} \varepsilon_{a} \sigma T_{a}^{4}-\varepsilon_{E} \sigma T_{E}^{4}-H-E=0,
$$

where $T_{E}$ and $T_{a}$ are, again, considered as homogeneous temperature (even though these temperatures are volume-averaged temperatures for the upper layer of an aqua-planet and the whole atmosphere, respectively [21]). Here, $\left(1-\varepsilon_{a}\right) \varepsilon_{E} \sigma T_{E}^{4}$ is the infrared radiation that is propagating through the atmosphere (it also includes the terrestrial radiation that is passing through the atmospheric window). Furthermore, the reflection of infrared radiation at the Earth's surface is included here, but scattering of infrared radiation in the cloudless atmosphere is ignored, in accord with Möller [90] and Kramm and Dlugi [21]. The latter substantially agrees with the fact that in the radiative transfer equation the Planck function is considered as the only source function when a non-scattering medium is in local thermodynamic equilibrium so that a beam of monochromatic intensity passing through the medium will undergo absorption and emission simultaneously, as described by Schwarzschild's equation [15,91,92]. Note that Arrhenius [93] considered a similar scheme for a column of the atmosphere, i.e., he already included the absorption of solar radiation by atmospheric constituents and the exchange of heat between the Earth's surface and the atmosphere. Furthermore, Miskolczi [94] also used such a Dines-type scheme.

The solution of the non-linear pair of equations is given by $[21,77]$

$$
T_{a}=\left\{\frac{\left(A_{a}+\varepsilon_{a}\left(1-\alpha_{E}-A_{a}\right)\right) \frac{S}{4}}{\varepsilon_{a} \sigma\left(1+\varepsilon_{E}\left(1-\varepsilon_{a}\right)\right)}+\frac{\left(1-\varepsilon_{a}\right)(H+E)}{\varepsilon_{a} \sigma\left(1+\varepsilon_{E}\left(1-\varepsilon_{a}\right)\right)}\right\}^{\frac{1}{4}}
$$

and

$$
T_{E}=\left\{\frac{\left(\left(1+\varepsilon_{E}\right)\left(1-\alpha_{E}\right)-A_{a}\right) \frac{S}{4}-H-E}{\varepsilon_{E} \sigma\left(1+\varepsilon_{E}\left(1-\varepsilon_{a}\right)\right)}\right\}^{\frac{1}{4}}
$$

It is obvious that $T_{E}$ and $T_{a}$ are dependent on the emissivity values of the Earth and the atmosphere, respectively, the atmospheric absorptivity in the solar range and the planetary albedo. Results provided by Eqs. 4.7 and 4.8 using $\alpha_{E}=0.30$ and some combinations of $\varepsilon_{E}$ and $\varepsilon_{a}$, where $A_{a}$ is ranging from zero to 0.3 , are illustrated in Figure 19. Assuming, for instance, that the atmosphere acts as blackbody emitter leads to an atmospheric temperature of $T_{a}=254.9 \mathrm{~K}$ which is independent of $A_{a}$. This temperature completely agrees with $T_{e}$ predicted on the basis of Eq.3.4. This is not surprising because for $\varepsilon_{a}=1$ the Eqs.3.4 and 4.7 would be equivalent. Considering, in addition, the Earth as a blackbody emitter provides a surface temperature of about $T_{E}$ $=286.4 \mathrm{~K}$ if $A_{a}$ is assumed to be zero.

This temperature hardly differs from $\left\langle T_{n s}\right\rangle=288 \mathrm{~K}$. However, in such a case the infrared net radiation would

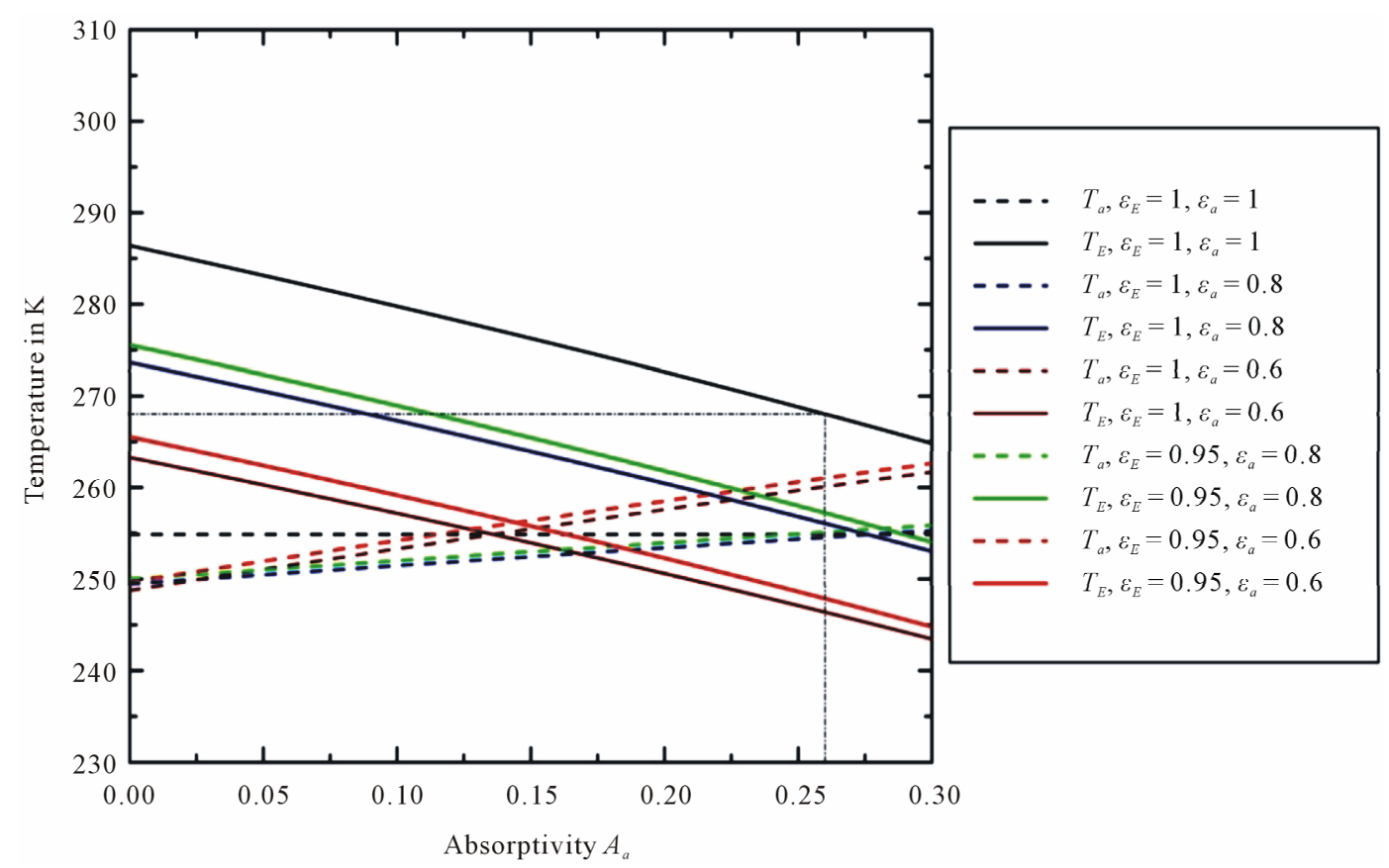

Figure 19. Uniform temperatures for the Earth's surface and the atmosphere provided by the two-layer model of a global energy-flux budget versus absorptivity $A_{a}$ (adopted from [21,77]). 
amount to $\Delta R_{L \uparrow}=\sigma\left(T_{E}^{4}-T_{a}^{4}\right)=142 \mathrm{~W} \cdot \mathrm{m}^{-2}$. This value is much larger than all $\Delta R_{L \uparrow}$ values listed in Table 2. Note that in case of $\varepsilon_{E}=0.95$ and $\varepsilon_{a}=0.6$ the Earth's surface temperature would be lower than the temperature of the radiative equilibrium of $T_{e}=254.9 \mathrm{~K}$ for $A_{a} \geq 0.17$, i.e., the Earth's surface temperature would be lower than the temperature of the atmosphere. In such a case it has to be expected that, at least, the sensible heat flux should change its direction. For $\varepsilon_{E}=1.0, \varepsilon_{a}=0.8$ and $A_{a}=0.23$ the Earth's surface temperature would only be slightly higher than $T_{e}$. In this case the temperature of the atmosphere would be $T_{a}=254.9 \mathrm{~K}$, i.e., it would correspond to the vertically averaged temperature of the troposphere. Consequently, it is forbidden to insert the globally averaged near-surface temperature, $\left\langle T_{n s}\right\rangle=288 \mathrm{~K}$, into such a global energy-flux scheme.

\section{SUMMARY AND CONCLUSIONS}

In this paper, we scrutinized the atmospheric greenhouse effect, where we debated the meaning of climate, climate change, climate variability and climate variation to outline in which way this effect might be responsible for climate change and climate variability, respectively. In doing so, we distinguished between two different branches of climatology, namely 1) physical climatology and 2) statistical climatology. We argued that studying 1) the input of solar energy into the system Earth-atmosphere, 2) the temporal and spatial distribution of this energy in the atmosphere and the oceans by radiative transfer processes, circulation systems and cycles, governed by fundamental geophysical fluid dynamic processes, 3) the absorption of solar irradiance in the underlying soil, 4) the exchange of energy between the Earth's surface and the atmosphere by the fluxes of sensible and latent heat and the infrared net radiation and 5) the long-term coinage of the boundary conditions of the respective climate system under study is the scope of the physical climatology. We described, for instance, how the daily solar insolation at the TOA is varying with latitude and time of the year, not only for present day orbital parameters, but also for long-term scales of many thousands of years, where we paid attention to Milankovitch's [33] astronomical theory of climatic variations.

On the contrary, the scope of the statistical climatology is the statistical description of weather states over long-term periods of, at least, thirty years to characterize the climate of locations, regions or even climate zones by mean values and higher statistical moments like variance (or its positive square root, called the standard deviation), skewness and kurtosis. We argued that climate change or climate variability can only be identified on the basis of two non-overlapping climate periods for which, at least, 60 year-observation records are required.
From the perspective of the statistical description of weather states as described before, we have to acknowledge that trends often considered as an indication for climate change are rather inappropriate in describing climate change and climate variability, respectively.

In fathoming whether the atmospheric greenhouse conjecture is really falsified as Gerlich and Tscheuschner [2] claimed or the notion "atmospheric greenhouse effect" is only a misnomer that describes a real effect, we scrutinized two completely different explanations of the atmospheric greenhouse effect: First, the explanation of the AMS and the WMO, secondly, the explanation of Ramanathan et al. [1]. Both explanations are related to the global scale. This relation could be the reason why often the notion 'global climate' is used and the debate on climate change is mainly focused on global climate change. However, as outlined in our paper, the notion "global climate" is a contradiction in terms.

We showed that the explanation by AMS and W·MO related to the temperature difference $\Delta T=\left\langle T_{n s}\right\rangle-T_{e} \approx$ $33 \mathrm{~K}$, where $\left\langle T_{n s}\right\rangle=288 \mathrm{~K}$ is the globally averaged near-surface temperature and $T_{e} \cong 255 \mathrm{~K}$ is the temperature of the planetary radiative equilibrium, has to be discarded because of physical reasons. As argued in Section 3, various assumptions on which $T_{e}$ is based are, by far, not fulfilled. Furthermore, the temperature of the planetary radiative equilibrium estimated for the Moon, $T_{e}=269.9 \mathrm{~K}$, is much higher than the Moon's averaged disk temperature of about $213 \mathrm{~K}$ obtained by Monstein [78] at $2.77 \mathrm{~cm}$ wavelength. Moreover, comparing $T_{e}$ with $\left\langle T_{n s}\right\rangle$ is rather inappropriate because the meaning of these two temperatures is quite different. The former is based on an energy-flux budget at the surface even though it is physically inconsistent because a uniform temperature for the entire globe does not exist; whereas the latter is related to the global average of observed near-surface temperatures. We argued that only the average temperature inferred from Eq.3.8 is comparable with $\left\langle T_{n s}\right\rangle=288 \mathrm{~K}$. Consequently, the argument of Gerlich and Tscheuschner [2] that this $33 \mathrm{~K}$ is a meaningless number is quite justified.

We showed on the basis of a Dines-type energy-flux budget for the Earth-atmosphere system that Fortak's [31] forty years old statement that the "cycle" of the longwave radiation between that Earth's surface and the atmosphere does not contribute to the heating of the system must not be rejected. Even though there is a large scatter (see Table 2), the results of various researchers confirm Fortak's [31] statement, too. Thus, we acknowledged Fortak's [31] argument that the outgoing emission of infrared radiation only serves to maintain the radiative equilibrium at the TOA.

We also showed that the globally averaged near-sur- 
face temperature of $\left\langle T_{n s}\right\rangle=288 \mathrm{~K}$ cannot be thermodynamically related to the Dines-type energy-flux budget for the Earth-atmosphere system because the temperatures $T_{E}$ and $T_{a}$ are volume-averaged quantities [21]. Thus, the related long-wave emission by the Earth's surface of about $390 \mathrm{~W} \cdot \mathrm{m}^{-2}$ is meaningless in such an energy-flux budget. Consequently, the explanation of the atmospheric greenhouse effect by Ramanathan et al. [1] is physically inappropriate.

Based on our findings, we conclude that 1) the socalled atmospheric greenhouse effect cannot be proved by the statistical description of fortuitous weather events that took place in past climate periods, 2) the description by AMS and WMO has to be discarded because of physical reasons, 3) energy-flux budgets for the Earthatmosphere system do not provide tangible evidence that the atmospheric greenhouse effect does exist. Because of this lack of tangible evidence it is time to acknowledge that the atmospheric greenhouse effect and especially its climatic impact are based on meritless conjectures.

\section{REFERENCES}

[1] Ramanathan, V., Callis, L., Cess, R., Hansen, J., Isaksen, I., Kuhn, W., Lacis, A., Luther, F., Mahlman, J., Reck, R. and Schlesinger, M. (1987) Climate-chemical interactions and effects of changing atmospheric trace gases. Reviews of Geophysics, 25, 1441-1482. doi:10.1029/RG025i007p01441

[2] Gerlich, G. and Tscheuschner, R.D. (2009) Falsification of the atmospheric $\mathrm{CO}_{2}$ greenhouse effects within the frame of physics. International Journal of Modern Physics B, 23, 275-364. doi:10.1142/S021797920904984X

[3] Halpern, J.B., Colose, C.M., Ho-Stuart, C., Shore, J.D., Smith, A.P. and Zimmermann, J. (2010) Comment on "Falsification of the atmospheric $\mathrm{CO}_{2}$ greenhouse effects within the frame of physics". International Journal of Modern Physics B, 24, 1309-1332. doi:10.1142/S021797921005555X

[4] Gerlich, G. and Tscheuschner, R.D. (2010) Reply to "comment on 'falsification of the atmospheric $\mathrm{CO}_{2}$ greenhouse effects within the frame of physics' by Joshua B. Halpern, Christopher M. Colose, Chris HoStuart, Joel D. Shore, Arthur P. Smith, Jorg Zimmermann". International Journal of Modern Physics B, 24, 13331359. doi:10.1142/S0217979210055573

[5] Planck, M. (1913) Vorlesungen über die Theorie der Wärmestrahlung. Verlag Johann Ambrosius Barth, Leipzig.

[6] Fortak, H. (1979) Entropy and climate. In: Bach, W., Pankrath, J. and Kellogg, W., Eds., Man's Impact on Climate, Elsevier Scientific Publishing Company, Amsterdam/Oxford/New York, 1-14.

[7] Zhang, Z.M. and Basu, S. (2007) Entropy flow and generation in radiative transfer between surfaces. International Journal of Heat and Mass Transfer, 50, 702-712. doi:10.1016/j.ijheatmasstransfer.2006.07.009

[8] Stephens, G.L. and Obrien, D.M. (1993) Entropy and climate. I: Erbe observations of the entropy production of the Earth. Quarterly Journal of the Royal Meteorological Society, 119, 121-152. doi:10.1002/qj.49711950906

[9] Wright, S.E., Scott, D.S., Haddow, J.B. and Rosen, M.A. (2001) On the entropy of radiative heat transfer in engineering thermodynamics. International Journal of Engineering Science, 39, 1691-1706. doi:10.1016/S0020-7225(01)00024-6

[10] Monin, A.S. and Shishkov, Y.A. (2000) Climate as a problem in physics. Uspekhi Fizicheskikh Nauk, 170, 419-445. doi:10.3367/UFNr.0170.200004d.0419

[11] Schönwiese, C.-D. (2005) Globaler und regionaler Klimawandel-Eine aktuelle wissenschaftliche Übersicht J.-W. Goethe University, Fankfurt.

[12] Gerlich, G. (2005), Zur Physik und Mathematik globaler Klimamodelle. In: Presentation before the TheodorHeuss-Akademie, Gummersbach, Germany.

[13] Hantel, M. (1997) Klimatologie. Bergmann, schaeferLehrbuch der Experimentalphysik, Band 7, Erde und Planeten. Walter de Gruyter, Berlin/New York, 311-426.

[14] Peel, M.C., Finlayson, B.L. and Mcmahon, T.A. (2007) Updated world map of the Köppen-Geiger climate classification. Hydrology and Earth System Sciences, 11, 16331644. doi:10.5194/hess-11-1633-2007

[15] Liou, K.N. (2002) An introduction to atmospheric radiation-Second edition. Academic Press, San Diego.

[16] Loutre, M.F., Paillard, D., Vimeux, F. and Cortijo, E. (2004) Does mean annual insolation have the potential to change the climate? Earth and Planetary Science Letters, 221, 1-14. doi:10.1016/S0012-821X(04)00108-6

[17] Berger, A. (1978) Long-term variations of daily insolation and Quaternary climatic changes. Journal of the Atmospheric Sciences, 35, 2362-2367. doi:10.1175/1520-0469(1978)035<2362:LTVODI $>2.0 . C$ $\mathrm{O} ; 2$

[18] Berger, A. (1988) Milankovitch theory and climate. Reviews of Geophysics, 24, 624-657.

[19] Mittelstaedt, P. (1970) Klassische mechanik. Bibliographisches Institut, Mannheim.

[20] Greiner, W. (1977) Theoretische physik, band 1, mechanik I. Verlag Harry Deutsch, Frankfurt am Main, Germany.

[21] Kramm, G. and Dlugi, R. (2010) On the meaning of feedback parameter, transient climate response and the greenhouse effect: Basic considerations and the discussion of uncertainties. The Open Atmospheric Science Journal, 4, 137-159. doi:10.2174/1874282301004010137

[22] Kondratyev, K.Y. (1969) Radiation in the Atmosphere. Academic Press, New York/London.

[23] Iqbal, M. (1983) An introduction to solar radiation. Academic Press, Canada.

[24] Haltiner, G.J. and Martin, F.L. (1957) Dynamical and physical meteorology. McGraw-Hill Book Company, New York/Toronto/London.

[25] Möller, F. (1973) Einführung in die Meteorologie. Bibliographisches Institut, Mannheim/Wien/Zürich.

[26] Vardavas, I.M. and Taylor, F.W. (2007) Radiation and climate. Oxford University Press, Oxford. doi:10.1093/acprof:oso/9780199227471.001.0001

[27] Petty, G.W. (2004) A first course in atmospheric radiation. Sundog Publishing, Madison, WI.

[28] Bohren, C.F. and Clothiaux, E.E. (2006) Fundamentals of 
atmospheric radiation. Wiley-VCH, Berlin. doi:10.1002/9783527618620

[29] Planck, M. (1901) Ueber das gesetz der energieverteilung im normalspectrum. Annalen der Physik, 4, 553-563. doi:10.1002/andp.19013090310

[30] Goody, R.M. and Yung, Y.L. (1989) Atmospheric radiation: Theoretical basis. Oxford University Press, New York/Oxford.

[31] Fortak, H. (1971) Meteorologie. Deutsche Buch-Gemeinschaft, Berlin/Darmstadt/Wien.

[32] Peixoto, J.P. and Oort, A.H. (1992) Physics of climate. American Institute of Physics, New York.

[33] Milankovitch, M. (1941) Kanon der Erdbestrahlungen und seine Anwendung auf das Eiszeitenproblem. Royal Serbian Academy, Section of Mathematical and Natural Sciences, 33, Belgrade.

[34] Bretagnon, P. (1974) Termes a longues periodes dans le systeme solaire. Astronomy \& Astrophysics, 30, 141-154.

[35] Lindzen, R.S. (1994) Climate dynamics and global change. Annual Review of Fluid Mechanics, 26, 353-378. doi:10.1146/annurev.f1.26.010194.002033

[36] Crowley, T.J. and North, G.R. (1991) Paleoclimatology. Oxford University Press, New York.

[37] Budó, A. (1990) Theoretische Mechanik. VEB Deutscher Verlag der Wissenschaften, Berlin.

[38] Bretagnon, P., Fienga, A. and Simon, J.L. (2003) Expressions for precession consistent with the IAU 2000A model-Considerations about the ecliptic and the Earth Orientation Parameters. Astronomy \& Astrophysics, 400, 785-790. doi:10.1051/0004-6361:20021912

[39] Capitaine, N., Wallace, P.T. and Chapront, J. (2005) Improvement of the IAU 2000 precession model. Astronomy \& Astrophysics, 432, 355-367.

[40] Hilton, J.L., Capitaine, N., Chapront, J., Ferrandiz, J.M., Fienga, A., Fukushima, T., Getino, J., Mathews, P., Simon, J.-L., Soffel, M., Vondrak, J., Wallace, P. and Williams, J. (2006) Report of the international astronomical union division I. Working group on precession and the ecliptic. Celestial Mechanics and Dynamical Astronomy, 94, 351-367. doi:10.1007/s10569-006-0001-2

[41] Berger, A. and Loutre, M.F. (1991) Insolation values for the climate of the last 10000000 years. Quaternary Science Reviews, 10, 297-317. doi:10.1016/0277-3791(91)90033-Q

[42] Berger, A., Loutre, M.F. and Tricot, C. (1993) Insolation and earths orbital periods. Journal of Geophysical Research-Atmospheres, 98, 10341-10362. doi:10.1029/93JD00222

[43] Brasseur, G.P. and Solomon, S. (2005) Aeronomy of the middle atmosphere. Springer, Dordrecht, The Netherlands.

[44] Trenberth, K.E., Fasullo, J.T. and Kiehl, J. (2009) Earth's global energy budget. Bulletin of the American Meteorological Society, 90, 311-323. doi:10.1175/2008BAMS2634.1

[45] Zipser, E.J. (2003) Some views on "hot towers" after 50 years of tropical field programs and two years of TRMM data. Meteorological Monographs, 29, 49-58.

[46] Tao, W.-K., Halverson, J., Lemone, M., Adler, R., Garstang, M., Houze Jr., R., Pielke Sr., R.A. and Woodley, W. (2003) The research of Dr. Joanne Simpson: Fifty years investigating hurricanes, tropical clouds and cloud sys- tems. Meteorological Monographs, 29, 1-15.

[47] Fierro, A.O., Simpson, J., Lemone, M.A., Straka, J.M. and Smull, B.F. (2009) On how hot towers fuel the hadley cell: An observational and modeling study of lineorganized convection in the equatorial trough from TOGA COARE. Journal of the Atmospheric Sciences, 66, 2730-2746. doi:10.1175/2009JAS3017.1

[48] Lindzen, R.S. and Pan, W. (1993) A note on orbital control of equator-pole heat fluxes. Climate Dynamics, 10, 49-57. doi:10.1007/BF00210336

[49] Kidder, S.Q. and Vonder Haar, T.H. (1995) Satellite meteorology. Academic Press, San Diego/New York/Boston/ London/Sydney/Tokyo/Toronto.

[50] Deardorff, J.W. (1978) Efficient prediction of ground surface temperature and moisture, with inclusion of a layer of vegetation. Journal of Geophysical Research, 83C, 1889-1903. doi:10.1029/JC083iC04p01889

[51] Mccumber, M.C. (1980) A numerical simulation of the influence of heat and moisture fluxes upon mesoscale circulation. University of Virginia, Charlottesville.

[52] Pielke, R.A. (1984) Mesoscale Meteorological Modeling. Academic Press, Orlando.

[53] Meyers, T. and Paw U, K.T. (1986) Testing of a higherorder closure model for modeling airflow within and above plant canopies. Boundary-Layer Meteorology, 37, 297-311. doi:10.1007/BF00122991

[54] Meyers, T. and Paw, U.K.T. (1987) Modelling the plant canopy micrometeorology with higher-order closure principles. Agricultural and Forest Meteorology, 41, 143-163. doi:10.1016/0168-1923(87)90075-X

[55] Sellers, P.J., Mintz, Y., Sud, Y.C. and Dalcher, A. (1986) A simple biosphere model (Sib) for use within generalcirculation models. Journal of the Atmospheric Sciences, 43, 505-531. doi:10.1175/1520-0469(1986)043<0505:ASBMFU $>2.0$. $\mathrm{CO} ; 2$

[56] Braud, I., Dantasantonino, A.C., Vauclin, M., Thony, J.L. and Ruelle, P. (1995) A simple soil-plant-atmosphere transfer model (Sispat) development and field verification. Journal of Hydrology, 166, 213-250. doi:10.1016/0022-1694(94)05085-C

[57] Kramm, G., Beier, N., Foken, T., Muller, H., Schroder, P. and Seiler, W. (1996) A SVAT scheme for $\mathrm{NO}, \mathrm{NO}_{2}$ and $\mathrm{O}_{3}$-Model description and test results. Meteorology and Atmospheric Physics, 61, 89-106. doi:10.1007/BF01029714

[58] Kramm, G., Dlugi, R., Müller, H. and Paw U, K.T. (1998) Numerische untersuchungen zum austausch von impuls, sensibler wärme und masse zwischen atmosphäre und hoher vegetation. Annalen der Meteorologie, 37, 475476.

[59] Ziemann, A. (1998) Numerical simulation of meteorological quantities in and above forest canopies. Meteorologische Zeitschrift, 7, 120-128.

[60] Su, H.B., Shaw, R.H. and Paw, U.K.T. (2000) Two-point correlation analysis of neutrally stratified flow within and above a forest from large-eddy simulation. BoundaryLayer Meteorology, 94, 423-460. doi:10.1023/A:1002430213742

[61] Pyles, R.D., Weare, B.C. and Paw U, K.T. (2000) The UCD advanced canopy-atmosphere-soil algorithm: Comparisons with observations from different climate and 
vegetation regimes. Quarterly Journal of the Royal Meteorological Society, 126, 2951-2980. doi:10.1002/qj.49712656917

[62] Pyles, R.D., Weare, B.C., Paw, U.K.T. and Gustafson, W. (2003) Coupling between the University of California, Davis, Advanced Canopy-Atmosphere-Soil Algorithm (ACASA) and MM5: Preliminary results for July 1998 for western North America. Journal of Applied Meteorology, 42, 557-569. doi:10.1175/1520-0450(2003)042<0557:CBTUOC $>2.0$. $\mathrm{CO} ; 2$

[63] Mölders, N., Haferkorn, U., Döring, J. and Kramm, G. (2003) Long-term investigations on the water budget quantities predicted by the hydro-thermodynamic soil vegetation scheme (HTSVS) - Part I: Description of the model and impact of long-wave radiation, roots, snow and soil frost. Meteorology and Atmospheric Physics, 84, 115-135. doi:10.1007/s00703-002-0578-2

[64] Mölders, N., Haferkorn, U., Döring, J. and Kramm, G. (2003) Long-term investigations on the water budget quantities predicted by the hydro-thermodynamic soil vegetation scheme (HTSVS)_Part II: Evaluation, sensitivity and uncertainty. Meteorology and Atmospheric Physics, 84, 137-156. doi:10.1007/s00703-002-0596-0

[65] Pal Arya, S. (1988) Introduction to micrometeorology. Academic Press, San Diego/New York/Boston/London/ Sydney/Tokyo/Toronto.

[66] Stefan, J. (1879) Über die beziehung zwischen der wärmestrahlung und der temperatur. Wiener Ber. II, 79, 391-428.

[67] Boltzmann, L. (1884) Ableitung des stefan'schen gesetzes, betreffend die abhängigkeit der wärmestrahlung von der temperatur aus der electromagnetischen lichttheorie. Wiedemann's Annalen, 22, 291-294.

[68] Kramm, G. and Mölders, N. (2009) Planck's blackbody radiation law: Presentation in different domains and determination of the related dimensional constants. Journal of the Calcutta Mathematical Society, 5, 27-61.

[69] Harmel, R.D., Richardson, C.W., Hanson, C.L. and Johnson, G.L. (2002) Evaluating the adequacy of simulating maximum and minimum daily air temperature with the normal distribution. Journal of Applied Meteorology, 41, 744-753. doi:10.1175/1520-0450(2002)041<0744:ETAOSM>2.0. $\mathrm{CO} ; 2$

[70] Möller, F. (1964) Optics of the lower atmosphere. Applied Optics, 3, 157-166. doi:10.1364/AO.3.000157

[71] Hansen, J., Lacis, A., Rind, D., Russell, G., Stone, P., Fung, I., Ruedy, R. and Lerner, J. (1984) Climate sensitivity: Analysis of feedback mechanisms. In: Hansen, J.E. and Takahashi, T., Eds., Climate Processes and Climate Sensitivity, American Geophysical Union, Washington D.C., pp. 130-163. doi:10.1029/GM029p0130

[72] Hartmann, D.L. (1994) Global physical climatology. Academic Press, San Diego.

[73] Cremers, C.J., Birkebak, R.C. and White, J.E. (1971) Lunar surface temperature at tranquility base. AIAA Journal, 9, 1899-1903. doi:10.2514/3.50000

[74] Mukai, T., Tanaka, M., Ishimoto, H. and Nakamura, R. (1997) Temperature variations across craters in the polar regions of the Moon and Mercury. Advances in Space
Research, 19, 1497-1506. doi:10.1016/S0273-1177(97)00348-7

[75] Vasavada, A.R., Paige, D.A. and Wood, S.E. (1999) Near-surface temperatures on Mercury and the Moon and the stability of polar ice deposits. Icarus, 141, 179-193. doi:10.1006/icar.1999.6175

[76] Budyko, M.I. (1977) Climatic change. American Geophysical Union, Washington DC.

[77] Kramm, G., Dlugi, R. and Zelger, M. (2009) Comments on the "Proof of the atmospheric greenhouse effect" by Arthur P. Smith. http://arxiv.org/abs/0904.2767v3

[78] Monstein, C. (2001) The Moon's temperature at $1=2.77$ $\mathrm{cm}$. ORION, 4.

[79] Piddington, J.H. and Minnett, H.C. (1949) Microwave thermal radiation from the Moon. Australian Journal of Scientific Research A, 2, 63-77.

[80] Pierrehumbert, R.T. (2011) Infrared radiation and planetary temperature. Physics Today, 64, 33-38. doi:10.1063/1.3541943

[81] Lacis, A.A., Schmidt, G.A., Rind, D. and Ruedy, R.A. (2010) Atmospheric $\mathrm{CO}_{2}$ : Principal control knob governing Earth's temperature. Science, 330, 356-359. doi:10.1126/science. 1190653

[82] Wien, W. (1896) Ueber die energieverteilung im emissionsspectrum eines schwarzen körpers. Annalen der Physik, 58, 662-669.

[83] Wien, W. (1894) Temperatur und entropie der strahlung. Annalen der Physik, 52, 132-165. doi:10.1002/andp.18942880511

[84] Dines, W.H. (1917) The heat balance of the atmosphere. Quaterly Journal of the Royal Meteorological Society, 43, 151-158. doi:10.1002/qj.49704318203

[85] Möller, F. (1963) On the influence of changes in the $\mathrm{CO}_{2}$ concentration in air on the radiation balance of the earth's surface and on the climate. Journal of Geophysical Research, 68, 3877-3886.

[86] Lorenz, E.N. (1967) The Nature and theory of the general circulation of the atmosphere. World Meteorological Organization, Geneva.

[87] Bernhardt, K. and Lauter, E.A. (1977) Globale physikalische prozesse und umwelt. Zeitschrift $f$. Meteorologie, 27, 1-20.

[88] Holton, J.R. (1979) An introduction to dynamic meteorology. Academic Press, New York/San Francisco/London.

[89] Kramm, G. and Meixner, F.X. (2000) On the dispersion of trace species in the atmospheric boundary layer: A re-formulation of the governing equations for the turbulent flow of the compressible atmosphere. Tellus, $\mathbf{5 2 A}$, 500-522.

[90] Möller, F. (1973) Geschichte der meteorologischen Strahlungsforschung. Promet, 2, 1-23.

[91] Chandrasekhar, S. (1960) Radiative transfer. Dover Publications, New York.

[92] Lenoble, J. (1993) Atmospheric radiative transfer. A. Deepak Publishing, Hampton, VA.

[93] Arrhenius, S. (1896) On the influence of carbonic acid in the air upon the temperature of the ground. Philosophical Magazine, 41, 237-275.

[94] Miskolczi, F.M. (2007) Greenhouse effect in semitransparent planetary atmospheres. Idöjárás, 111, 1-40.

[95] Kiehl, J.T. and Trenberth, K.E. (1997) Earth's annual 
global mean energy budget. Bulletin of the American Meteorological Society, 78, 197-208. doi:10.1175/1520-0477(1997)078<0197:EAGMEB $>2.0$. $\mathrm{CO} ; 2$

[96] United States Committee for the Global Atmospheric Research Program. (1975) Understanding climatic change: A program for action. National Academy of Sciences, Washington DC.

[97] Budyko, M.I. (1982) The Earth's climate, past and future. Academic Press, New York.

[98] Paltridge, G.W. and Platt, C.M.R. (1976) Radiative processes in meteorology and climatology. Elsevier Scientific Pub. Co., Amsterdam /New York.

[99] Ramanathan, V. (1987) The role of earth radiation budget studies in climate and general-circulation research. Journal of Geophysical Research-Atmospheres, 92, 4075-4095. doi:10.1029/JD092iD04p04075

[100] Schneider, S.H. (1987) Climate modeling. Scientific American, 256, 72-80. doi:10.1038/scientificamerican0587-72

[101] Maccracken, M.C. (1985) Carbon dioxide and climate change: Background and overview. In: Maccracken, M.C. and Luther, F.M., Eds., Projecting the Climatic Effects of Increasing Carbon Dioxide, U.S. Department of Energy, pp. 1-23.

[102] Henderson-Sellers, A. and Robinson, P.J. (1986) Contemporary climatology. Longman Scientific \& Technical, Wiley, London/New York.

[103] Rossow, W.B. and Zhang, Y.C. (1995) Calculation of surface and top of atmosphere radiative fluxes from physical quantities based on ISCCP data sets 2 . Validation and first results. Journal of Geophysical Research-
Atmospheres, 100, 1167-1197.

[104] Fu, Q. (2003) Radiation (SOLAR). In: Holton, J.R., Ed., Encyclopedia of Atmospheric Sciences, Academic Press, Oxford, 1859-1863.

[105] Berger, A. (1992) Orbital Variations and insolation database. In: IGBP PAGES/World Data Center for Paleoclimatology Data Contribution Series \# 92-007, NOAA/ NGDC Paleoclimatology Program, Boulder, CO.

[106] Hasse, L. (1971) The sea surface temperature deviation and the heat flow at the sea-air interface. BoundaryLayer Meteorology, 1, 368-379. doi:10.1007/BF02186037

[107] Meehl, G.A., Karl, T., Easterling, D.R., Changnon, S., Pielke, R., Changnon, D., Evans, J., Groisman, P.Y., Knutson, T.R., Kunkel, K.E., Mearns, L.O., Parmesan, C., Pulwarty, R., Root, T., Sylves, R.T., Whetton, P. and Zwiers, F. (2000) An introduction to trends in extreme weather and climate events: Observations, socioeconomic impacts, terrestrial ecological impacts and model projections. Bulletin of the American Meteorological Society, 81, 413-416.

doi:10.1175/1520-0477(2000)081<0413:AITTIE $>2.3$.CO ;2

[108] Forster, P., et al. (2007) Changes in atmospheric constituents and in radiative forcing. In: Solomon, S., Qin, D., Manning, M., Chen, Z., Marquis, M., Averyt, K.B., Tignor, M. and Miller. H.L., Eds., Climate Change 2007: The Physical Science Basis-Contribution of Working Group I to the Fourth Assessment Report of the Intergovernmental Panel on Climate Change, Cambridge University Press, Cambridge/New York, 129-234. 